\title{
Application of a Laser Induced Fluorescence Model to the Numerical Simulation of Detonation Waves in Hydrogen-Oxygen-Diluent Mixtures
}

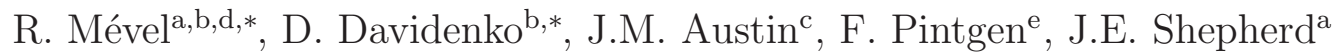 \\ ${ }^{a}$ Graduate Aeronautical Laboratories, California Institute of Technology, Pasadena, USA \\ ${ }^{b}$ Institut de Combustion, Aérothermique, Réactivité et Environnement, Orléans, France \\ ${ }^{c}$ University of Illinois, Department of Aerospace Engineering, Urbana, USA \\ ${ }^{d}$ University of Orléans, Department of Chemistry, Orléans, France \\ ${ }^{e}$ Cheniere Energy, Houston, USA
}

\begin{abstract}
A laser-induced-fluorescence model has been implemented and used to post-process detonation wave numerical simulation results to allow a direct comparison with previous experimental visualizations of detonations in hydrogen-oxygen-diluent mixtures. The model is first applied to steady one-dimensional simulation results obtained with detailed chemistry. The effects on the fluorescence intensity of the model parameters are examined to explore the dominant processes. The dominant interference process in the experiments carried out to date is the absorption of incident laser light by the high concentration of $\mathrm{OH}$ in and behind the reaction zone. The model is then applied to unsteady two-dimensional simulation results obtained with reduced chemical schemes to obtain synthetic PLIF image. The results demonstrate good qualitative agreement between the experimental and calculated laser-inducedfluorescence intensities. The model limitations and the experimental uncertainties are discussed together with a critical evaluation of the modeling approach.

Keywords: Hydrogen, Oxygen, Detonation structure, Numerical simulation, Planar laser-induced-fluorescence

PACS: 47.40.Rs, 47.11.Bc, 82.33.Vx, 42.62.Fi
\end{abstract}

*Corresponding author: mevel@caltech.edu 


\section{Nomenclature}

\section{ROMAN CHARACTERS:}

\begin{tabular}{|c|c|c|}
\hline$A$ & the A Einstein coefficient & {$[1 / \mathrm{s}]$} \\
\hline$A_{L}$ & the laser cross-sectional area & {$\left[\mathrm{m}^{2}\right]$} \\
\hline$B$ & the B Einstein coefficient & {$\left[\mathrm{m}^{2} / \mathrm{J} \cdot \mathrm{s}\right]$} \\
\hline$c$ & the speed of light & {$[\mathrm{m} / \mathrm{s}]$} \\
\hline$c_{2}$ & the second radiative constant & {$[\mathrm{m} \cdot \mathrm{K}]$} \\
\hline$C_{P}$ & the heat capacity at constant pressure & {$[\mathrm{J} / \mathrm{mol} . \mathrm{K}]$} \\
\hline$E^{\prime \prime}$ & the lower state energy & {$[1 / \mathrm{m}]$} \\
\hline$E_{L}$ & the laser energy per pulse & {$[\mathrm{J} /$ pulse $]$} \\
\hline$F$ & the fluorescence intensity & [A.U.] \\
\hline$f_{B}$ & the Bolzmann fraction & {$[-]$} \\
\hline$g^{\prime \prime}$ & the statistical weights of the lower state & {$[-]$} \\
\hline$h_{i}$ & the specific enthalpy of the i species & {$[\mathrm{J} / \mathrm{mol}]$} \\
\hline$I$ & the intensity of the laser & {$[$ A.U. $]$} \\
\hline$I_{b}$ & $\begin{array}{l}\text { a dimensionless factor accounting for the light sheet ab- } \\
\text { sorption }\end{array}$ & {$[-]$} \\
\hline
\end{tabular}


$I_{0} \quad$ the initial intensity of the laser

[A.U.]

$I_{\nu}^{0} \quad$ the normalized spectral laser irradiance

$[\mathrm{J} / \mathrm{m} \cdot \mathrm{s}]$

$k \quad$ the Boltzmann constant

$[\mathrm{J} / \mathrm{K}]$

$L_{L}$ the dimensionless spectral distribution function of the laser

$m_{A}$

the molecular mass of the absorbing molecule

$[\mathrm{kg} /$ molecule $]$

$M_{i}$

the molar mass of the i species

$[\mathrm{kg} / \mathrm{mol}]$

$\bar{M}_{m}$

the mixture molar mass

$[\mathrm{kg} / \mathrm{mol}]$

$n$

an exponent

$[-]$

$N b_{i} \quad$ the number of species

$[-]$

$N_{i}$

the number density of the i species

$\left[1 / \mathrm{m}^{3}\right]$

$N_{O H}$

the $\mathrm{OH}$ radicals number density

$\left[1 / \mathrm{m}^{3}\right]$

$P_{i}$

the partial pressure of the i species

$[\mathrm{Pa}]$

Q the quenching rate

$[1 / \mathrm{s}]$

$Q_{p} \quad$ the partition function

$[-]$

$S(T) \quad$ the spectral line strength at the temperature $\mathrm{T}$

$[\mathrm{m} /$ molecule $]$

$S\left(T_{\text {ref }}\right)$

the spectral line strength at the reference temperature

$[\mathrm{m} /$ molecule $]$ 
$T_{\text {ref }} \quad$ the reference temperature

$x \quad$ the absorbing medium length

$[\mathrm{m}]$

$X_{i} \quad$ the mole fraction of the i species

$Y_{C} \quad$ the collision-broadened line-shape function of the absorp- $[\mathrm{m}]$ tion line

$Y_{D}$ the Doppler line-shape function of the absorption line

\section{GREEK CHARACTERS:}

$\Delta \nu_{D} \quad$ the Doppler line width

$\Delta \nu_{L} \quad$ the laser line width collisional quenching cross section expression 


\begin{tabular}{|c|c|c|}
\hline$\gamma_{0 i}$ & $\begin{array}{l}\text { the collision coefficient of the i species at a reference tem- } \\
\text { perature }\end{array}$ & {$[1 / \mathrm{m} \cdot \mathrm{Pa}]$} \\
\hline$\nu$ & the wave number & {$[1 / \mathrm{m}]$} \\
\hline$\nu_{0}$ & the absorption line center wave number & {$[1 / \mathrm{m}]$} \\
\hline$\nu_{0 L}$ & the laser center line wave number & {$[1 / \mathrm{m}]$} \\
\hline $\bar{\omega}_{i}$ & the rate of production of the i species & {$\left[\mathrm{kg} / \mathrm{s} \mathrm{m}^{3}\right]$} \\
\hline$\rho$ & the density & {$\left[\mathrm{kg} / \mathrm{m}^{3}\right]$} \\
\hline$\sigma_{i}$ & the absorption cross section of the i species & {$\left[\mathrm{m}^{2}\right]$} \\
\hline$\sigma_{Q i}$ & the collisional quenching cross section of the i species & {$\left[\mathrm{m}^{2}\right]$} \\
\hline$\sigma_{Q i}(\infty)$ & $\begin{array}{l}\text { the collisional quenching cross section of the i species at } \\
\text { infinit temperature }\end{array}$ & {$\left[\mathrm{m}^{2}\right]$} \\
\hline$\dot{\Sigma}$ & the thermicity & {$[1 / \mathrm{s}]$} \\
\hline
\end{tabular}




\section{Introduction}

Since the discovery of the detonation phenomenon by Berthelod and Vielle [1] and Mallard and Le Chatelier [2], many investigations have been carried out on the structure of detonation waves propagating in gaseous mixtures. In the late fifties, Voitsekhovskii [3] and Denisov and Troshin [4, 5], demonstrated the 3-dimensional nature of detonations waves, in contrast with the early Chapman-Jouguet $[6,7]$ and Zel'dovich-von Neumann-Döring, ZND, [8, 9, 10] theoretical models that assumed a planar geometry of the detonation front. The soot foil technique is being used extensively for over 50 years with major contributions by Strehlow [11], Libouton et al. [12] and Presles et al. [13], among many others. Time resolved soot foil studies $[14,15]$ and the mylar mirror deformation technique [16] have also been usefull to demonstrate the relationship between the cellular structure and the configuration of the shock front. The description of the detonation front structure has been considerably improved through direct visualization investigations using a variety of techniques such as interferometry [17, 18], compensated streak imaging [19], direct imaging [20], schlieren [21, 22, 23, 24] or Rayleigh scattering imaging [25].

In the two last decades, modern laser diagnostic techniques have enabled the imaging of chemical species within detonations; complementing the classical methods of density-based visualization of high-speed combustion [17, 18, 21, 22, 23]. Kamel et al. [26] and Viguier et al. [27] employed $\mathrm{OH}$ radical planar laser induced fluorescence (PLIF) to visualize the reaction zone structure behind oblique detonation waves. Austin et al. [28, 29] and Pintgen et al. [30, 31, 32] performed simultaneous visualization of detonations using schlieren and PLIF techniques. These studies enabled direct observation of the $\mathrm{OH}$ radical spatial distribution in the reaction zone. In weakly unstable detonations [31], the spatial distribution is characterized by alternating keystone-shaped features of high and low $\mathrm{OH}$ concentration created by the cellular structure of the detonation. In highly unstable detonations [29], other features such as shear layers, unreacted pockets, and fractal-like $\mathrm{OH}$ fronts are observed [33]. Similar PLIF reaction zone visualization experiments, but without schlieren imaging, have been performed by Wang et al. for methane-air mixtures [34]. Numerical simulations $[35,36]$ are able to qualitatively reproduce these geometric 
features, but direct comparison of the OH PLIF images has been so far limited to one-dimensional profiles using the ZND model as an approximation to the spatial structure normal to the front for weakly unstable waves [37].

Due to the dependence of the PLIF emission on many unknown factors other than just the $\mathrm{OH}$ concentration, it is not possible to simply and directly interpret the emission intensity quantitatively as the amount of $\mathrm{OH}$ present in the flow. As an alternative, we have created synthetic PLIF images based on two-dimensional (2D) numerical simulations. The simulations are post-processed to obtain the synthetic PLIF images by using a realistic but simplified model of the PLIF process. The detonation simulations are carried out using the unsteady, reactive, inviscid flow model with a detailed chemical reaction mechanism for $\mathrm{H}_{2}-\mathrm{O}_{2}$ mixtures. The resulting predictions of fluoresence intensity are compared with experimental results $[28,29]$ for weakly and moderately unstable cases with high argon and nitrogen dilution.

\section{Numerical simulation methods}

\subsection{Computational fluid dynamics code}

In addition to ZND simulations, for which a description can be found in Ref. [38], 2-D numerical simulations have been performed. Cellular detonations are simulated by solving the 2-D Euler equations with a high-resolution computer code based on the finite-difference method [39]. For the numerical flux approximation, the shockcapturing, weighted essentially non-oscillatory (WENO) scheme of the fifth order [40] is employed together with the Lax-Friedrichs splitting of fluxes in the characteristic form. For the time integration, the ASIRK2C second-order semi-implicit additive Runge-Kutta scheme [41] is used. The convective terms in the Euler equations are treated explicitly while the implicit treatment is applied to the source terms. The time step is controlled by the Courant-Friedrichs-Lewy stability condition limiting the Courant number to 0.7 .

For code validation, the following test cases were simulated, (i) constant-volume explosion in a homogeneous mixture, (ii) self-ignition in a steady-state supersonic flow, (iii) subsonic reacting flow in a steady-state overdriven detonation, (iv) shock tube problems, and (v) 2-D shock interactions. All these tests were in satisfactory 
agreement with the analytical or numerical solutions obtained with other numerical tools. Examples of validation cases are provided as a supplemental material.

The numerical solution is obtained on a structured orthogonal mesh within a rectangular computational domain. The mesh points are uniformly distributed in the direction normal to the detonation propagation. In the propagation direction, the mesh consists of a fine zone, near the inlet boundary, with a uniform mesh step and a zone with progressively increasing point spacing. The detonation front is kept within the first zone for better resolution. The second zone serves as a buffer between the detonation front and the outflow boundary.

Detonation wave propagation was simulated in a reference frame moving with the detonation wave at CJ velocity. To obtain a nearly stationary detonation front, a uniform flow at the CJ detonation velocity is imposed on the inlet boundary. CJ conditions are approached at some distance from the outlet boundary. Symmetry conditions are imposed on the two remaining boundaries. The ghost cell technique is used to implement the boundary conditions. This consists of 3 external rows of mesh points (the half width of the WENO stencil) along each edge of the computational domain. Conserved variables at the external (ghost) points are updated at each time iteration from the internal points or the imposed boundary values. For the inlet boundary, conserved variables at the ghost points assigned values of the fixed inlet conditions. At the outlet boundary, conditions in the ghost points are determined by solving a local Riemann problem for the flow state in the nearest internal point and the CJ state; this technique represents a characteristic-like treatment of the outflow condition. Ghost points along the two other boundaries are filled from 3 rows of internal points adjacent to the same boundary.

The 2-D solution is initialized from a corresponding 1-D ZND solution. The initial flowfield is randomly perturbed to provoke transverse instabilities within the detonation front. After a short time period, the solution evolves into a cellular pattern typical of realistic detonations. The simulation continues until the mean propagation velocity and the mean cell size stabilize. 


\subsection{Laser induced fluorescence model}

The hydroxyl radical laser induced fluorescence (LIF) diagnostic is widely used in combustion studies. Pintgen [30,37] reported measurements of PLIF images behind propagating detonation fronts and applied a model of the LIF process to one dimensional (ZND) detonation simulations which demonstrated quantitative agreement between measured and modeled intensities. Estimating the PLIF intensity behind a detonation front involves a number of physical processes that must be modeled in order to make quantitative estimates of fluorescence emission. A comprehensive description of the phenomenon requires taking into account hundreds of energy levels [42]. As this approach is impractical, requiring too much computational time and numerous unknown parameters to describe the energy transfer processes, a simplified model has been chosen in the present study. Based on Pintgen's results, Chapter 3 of [37], we adopted the simple three-level model of Bessler et al. [42] to simulate the LIF process. Figure 1 shows a schematic of the model. The energy transfer processes accounted for are: stimulated absorption, stimulated emission, spontaneous emission, quenching and rotational energy transfers. The rate of these processes are respectively referred to as $b_{12}, b_{21}, A_{21}$ and $A_{23 i}, Q$ and $R$. In the framework of the three-level model, the following assumptions are made to simplified the description of the LIF process: (i) the ground state rotational energy transfers are fast, (ii) the excited state rotational energy transfers are neglected, (iii) all allowed transitions between the excited state and the rovibrational levels of the ground state contribute to the fluorescence signal, and (iv) the photoionization and predissociation processes are neglected. The three level model of Figure 1 considers laser excitation from the ground state (1) to the upper state (2) and fluorescence emission due to transitions from (2) to all possible vibrational and rotational electronic ground states.

As calculated by Pintgen [37], the LIF experimental setup used for detonation imaging was in the linear regime. In this regime, the LIF signal intensity, F, of one single pumped transition is obtained from the steady-state rate equation [43] and is given by the following expression: 


$$
F \propto f_{B} \Gamma I_{\nu}^{0} I_{b} N_{O H} B \frac{1}{Q} \sum A_{i}
$$

In the present study, the contributions of the $\mathrm{A}^{2} \Sigma^{+} \leftarrow \mathrm{X}^{2} \Pi(1,0) \mathrm{Q}_{2}(8)$ and $\mathrm{A}^{2}$ $\Sigma^{+} \leftarrow \mathrm{X}^{2} \Pi(1,0) \mathrm{Q}_{1}(9)$ absorption lines, at $35210.25(284.0082 \mathrm{~nm})$ and 35210.68 $(284.0047 \mathrm{~nm}) \mathrm{cm}^{-1}$, respectively, were taken into account. The contributions of the adjacent absorption lines, namely $\mathrm{P}_{1}(5), \mathrm{Q}_{21}(9)$ and $\mathrm{Q}_{12}(8)$ at 35207.78 (284.0281 $\mathrm{nm}), 35208.66(284.0210 \mathrm{~nm})$ and $35212.05(283.9937 \mathrm{~nm}) \mathrm{cm}^{-1}$, respectively, were neglected due to the very narrow laser line used in the experiments. The LIF signal intensity was normalized with respect to the highest intensity value. Each of the quantities in Equation 1 are computed from standard models as discussed below.

The Boltzmann fraction was calculated using the following expression where $Q_{p}$, denoting the partition function, was taken from the HITRAN database [44]:

$$
f_{B}=\frac{g^{\prime \prime} \exp \left(-c_{2} \frac{E^{\prime \prime}}{T}\right)}{Q_{p}}
$$

The dimensionless overlap integral, $\Gamma$, was obtained from the following relationship $[45]:$

$$
\Gamma=\int_{-\infty}^{+\infty} Y_{A} L_{L} d \nu
$$

The spectral configuration is shown in Figure 2. The laser line-shape was assumed to be Gaussian with a center line at $35210.46 \mathrm{~cm}^{-1}(284.0065 \mathrm{~nm})$, located exactly halfway between the two absorption lines, and a full width at half maximum of 0.1 $\mathrm{cm}^{-1}$, as given below:

$$
L_{L}=\sqrt{\frac{4 \ln (2)}{\pi}} \exp \left(4 \ln (2)\left(\frac{\nu-\nu_{0 L}}{\Delta \nu_{L}}\right)^{2}\right)
$$

Neglecting the natural broadening, the absorption line-shape function was obtained from the Doppler and the collision-broadened line-shape functions by using the mod- 
ified pseudo-Voigt method proposed by Ida et al. [46]. The reported accuracy of this method, $0.12 \%$ relative to the peak height, was found satisfactory and avoid time consuming fitting of the exact Voigt profile. The Doppler and collision-broadened line-shape functions are respectively given by the following relationships:

$$
\begin{gathered}
Y_{D}=\frac{c}{\nu_{0}} \sqrt{\frac{m_{A}}{2 \pi k T}} \exp \left(-4 \ln (2) \frac{\left(\nu-\nu_{0}\right)^{2}}{\Delta \nu_{D}^{2}}\right) \\
Y_{C}=\frac{\Delta \nu_{C}}{2 \pi} \frac{1}{\left(\nu-\nu_{0}\right)^{2}+\left(\Delta \nu_{C} / 2\right)^{2}}
\end{gathered}
$$

The Doppler and collision line widths were respectively calculated from the two following expressions:

$$
\begin{gathered}
\Delta \nu_{D}=\frac{2 \nu_{0}}{c} \sqrt{\frac{2 k T \ln (2)}{m_{A}}} \\
\Delta \nu_{C}=\sum 2 \gamma_{i} P_{i}
\end{gathered}
$$

The temperature dependence of the collisional broadening coefficient was described using the expression of Rea et al. [47].

$$
2 \gamma_{i}=2 \gamma_{0 i}\left(\frac{T_{r e f}}{T}\right)^{n}
$$

The $2 \gamma$ and $n$ parameters were taken from available data $[44,47,48,49,50]$ for the $\mathrm{OH}$ radical $(0,0)$ band because of the lack of data for the $(1,0)$ band. The rotational level dependence of the collisional broadening coefficient studied by Kessler et al. [51] was neglected.

The normalized spectral laser irradiance was calculated following the formula given by Partridge and Laurendeau [45]:

$$
I_{\nu}^{0}=\frac{E_{L}}{A_{L} \Delta \nu_{L} \Delta t_{L}}
$$


The dimensionless factor accounting for the light sheet absorption as it travels through an absorbing medium was directly obtained from the Beer-Lambert law:

$$
I_{b}=\frac{I}{I_{0}}=\exp \left(-x \sum \sigma_{i} N_{i}\right)
$$

The absorbing species considered in the present study were $\mathrm{H}_{2} \mathrm{O}$ and $\mathrm{OH}$ radicals (two absorption lines for $\mathrm{OH}$ ); other species were found to contribute a negligible amount to absorption. The absorption cross section of $\mathrm{H}_{2} \mathrm{O}$ was taken from Schulz et al. [52] who give the dependence of $\sigma_{H 2 O}$ as a function of temperature in the wavelength range 190-320 nm. For the hydroxyl radicals, the temperature dependence of the absorption cross section was described using the following expression [37] where the spectral line strength at the reference temperature was taken from the HITRAN database [44]:

$$
\sigma_{O H}=Y_{A}(T) S\left(T_{r e f}\right) \frac{Q_{p}\left(T_{r e f}\right)}{Q_{p}(T)} \frac{\exp \left(-c_{2} \frac{E^{\prime \prime}}{T}\right)}{\exp \left(-c_{2} \frac{E^{\prime \prime}}{T_{r e f}}\right)} \frac{1-\exp \left(-c_{2} \frac{\nu_{0}}{T}\right)}{1-\exp \left(-c_{2} \frac{\nu_{0}}{T_{r e f}}\right)}
$$

The collisional quenching rate of the $\mathrm{OH}$ radicals was calculated from the expression proposed by Paul [53]:

$$
Q=\frac{P}{k T}\left(\frac{8 k T}{\pi m_{O H}}\right)^{1 / 2} \sum X_{i}\left(1+\frac{m_{O H}}{m_{i}}\right)^{1 / 2} \sigma_{Q i}
$$

The temperature dependence of the collisional quenching cross section, $\sigma_{Q i}$, was described using the formalism of Lin et al. [54, 55] rather than the Harpooned model $[53,56]$ :

$$
\sigma_{Q i}(T)=\sigma_{Q i}(\infty) \exp \left(\frac{\epsilon}{k_{Q}} \frac{1}{T}\right)
$$

Finally, the A and B Einstein coefficients were taken from the LIFBASE software database [57]. 


\section{Results}

\subsection{Experimental results}

Figure 3 shows a schematic of the experimental setup developed by Pintgen [30, 37] to perform simultaneous schlieren and PLIF imaging. An identical system was used by Austin et al. [28, 29] with a $4.2 \mathrm{~m}$ long rectangular narrow channel with a height of $152 \mathrm{~mm}$ and a width of $18 \mathrm{~mm}$. The detonation is initiated by a planar wave generated by a $\mathrm{C}_{2} \mathrm{H}_{2}-\mathrm{O}_{2}$ detonation created by a unique multi-channel initiator [58]. The detonation shock front and reaction zone are visualised through two $152 \mathrm{~mm}$ diameter quartz windows located close to the end of the narrow channel. By using a narrow channel, the instability is essentially two-dimensional and the images, PLIF and schlieren, can be easily interpreted.

Figure 4 shows a schlieren picture, a PLIF picture and a superimposition of both images. In the schlieren image, the incident and reflected shocks, the Mach strem and the triple points can clearly be seen. The leading shock is smooth and composed of alternant portions of different strength. The shock front appears as a sharp line with a smooth contour. No small scale structure can be seen in the picture. In the PLIF picture, the reaction zone of the detonation appears smooth and continuous and is characterised by keystone-like structures. These structures result from the differences in strength between the shock waves that form the front as discussed in Pintgen et al [31].

Despites the insights into the detonation structure provided by Pintgen [30] and Austin et al. [28, 29] experiments, no quantitative information about the $\mathrm{OH}$ radical density can be obtained directly from the PLIF images. The reasons for this are discussed in detail by Pintgen [30] and include: (i) locally varying quenching effects which influence the LIF signal strength; (ii) absorption of the light sheet energy by $\mathrm{OH}$ radicals; (iii) the ground state population depends on the local thermodynamic state; (iv) the incident light sheet gets refracted at the detonation front which can lead to low quality imaging; and (v) radiative trapping [59]. Due to the highly transient and unique nature of each image, it is not feasible to carry out detailed measurements of species, temperature, and pressure distributions that would be re-

quired in order to directly interpret the PLIF images. Instead, we have obtained the 
necessary information from numerical simulation using detailed chemical reaction mechanisms. We have then used the detailed information from the simulations to create synthetic PLIF images that can be compared with the measured images. The transient nature of the detonation process is addressed by carrying out comparisons at locations within the flowfield and times where the numerical and physical realizations appear to be in phase. This comparison is necessarily imprecise because for the cases we are examining the detonations transient structure is neither completely two dimensional nor precisely periodic in space and time.

\subsection{ZND simulation results}

ZND solutions were post-processed and compared to normalized LIF signal intensity extracted from the PLIF experimental images. The ZND solutions were computed using the Shock and Detonation toolbox [60] and the detailed chemical reaction model of Mével et al. [61, 62] which was validated for $\mathrm{H}_{2}-\mathrm{O}_{2}$ mixtures over a wide range of conditions including shock-tube, jet stirred and flow reactors, and flame speed experimental results [63]. The grey-scale PLIF images were analysed using a Matlab routine. The fluorescence intensity was averaged in the direction perpendicular to the propagation over $1 \mathrm{~cm}$ wide stripes oriented in the flow direction. The LIF intensity was then normalized with respect to the highest intensity value. This technique was first applied by Pintgen [37] to explain the observed features of the fluorescence signal behind the detonation front. The appearance of a sharp front is due to the exponential growth of $\mathrm{OH}$ (chain branching reactions) and the rapid decrease in intensity behind the front is mainly due to the absorption of the excitation laser by the high concentration of $\mathrm{OH}$ in the combustion products.

Figure 5 and Figure 6 present some examples of the results for detonations propagating in stoichiometric $\mathrm{H}_{2}-\mathrm{O}_{2}$ mixtures, with $80 \%$ Ar in Figure 5 and $65 \% \mathrm{~N}_{2}$ in Figure 6. Because the position of the shock wave is not known precisely in the experiment, the calculated LIF signal has been shifted so that calculated and experimental maxima locations coincide. The rapid rise and the decrease of the LIF signal intensity are qualitatively correct, the extent of quantitative agreement de- 
pends primarily on the estimated shock speed and laser line profile, and secondarily on the parameters in the LIF model. The effect of the laser center line position and width are illustrated in Figure 5. The model results with nominal parameters (given above) are shown as solid lines and model results with variations in the parameters are shown as dashed lines. The rate of decay of the LIF signal intensity with distance behind the peak is quite sensitive to both these parameters. The shift of the laser center line toward either one of the 2 absorption lines or the increase of the laser line width both result in a larger value of the overlap integral (Equation 3) and a faster decrease of the LIF signal with increasing distance behind the front. Figure 6 illustrates the effect of the $\mathrm{OH}$ radicals absorption cross sections and of the detonation velocity. Again, the model results with nominal parameters are shown as solid lines and model results with variations in the parameters are shown as dashed lines. A decrease of the absorption cross sections results in a noticeable reduction of the LIF intensity decay rate. If a slightly over-driven detonation ( $5 \%$ greater than $\left.\mathrm{D}_{C J}\right)$ is considered, the calculated LIF intensity decays only slightly faster than the CJ case. Also shown in Figure 5 and Figure 6 are the normalized mole fractions of $\mathrm{OH}$ radicals. Comparing the $\mathrm{LIF}$ and $\mathrm{OH}$ mole fraction profiles, we very clearly see the dramatic effect of absorption of the incident light sheet in reducing the fluorescence signal from $\mathrm{OH}$ radicals at large distances from the front. For example, at $2.5 \mathrm{~cm}$ behind the detonation front, the normalized LIF intensity ranges between 0.10 and 0.15, whereas the normalized $\mathrm{OH}$ mole fraction is on the order of 0.7-0.8. Figure 7 shows this effect by presenting the evolution of the spectrally resolved normalized laser intensity as a function of distance behind the shock front in a steady 1D ZND model of a detonation reaction zone for a stoichiometric $\mathrm{H}_{2}-\mathrm{O}_{2}$ mixtures, with $80 \%$ Ar. In the present model, a laser line width of $0.1 \mathrm{~cm}^{-1}$ and a laser center line just at the middle between the two absorption lines have been assumed. Because of this specific spectral configuration, neither a frequency shift of the maximum laser intensity nor non-uniform modification of the laser line shape with distance are induced by the absorption. Figure 8 illustrates the effect of the spectral configuration on the evolution of the laser intensity as a function of distance behind the shock front in a steady 1D ZND model of a detonation reaction zone. Lines in Figure 8 
represent iso-contours of normalized incident light intensity. In Figure 8 (a), the laser line width has been increased from 0.1 to $1 \mathrm{~cm}^{-1}$ whereas in Figure 8 (b), the laser center line has been shifted by $0.16 \mathrm{~cm}^{-1}(0.0012 \mathrm{~nm})$. These calculations demonstrate the sensitivity of the frequency of maximum intensity and of the laser line shape to the spectral configuration. The evolution of the laser intensity with distance indicates that the parameter controlling the LIF intensity is the absorption of the laser light. Figure 9 illustrates this feature by comparing the experimental LIF intensity with calculated ones obtained with the full model and with a simple model which corresponds to

$$
F \propto I_{b} \cdot N_{O H}
$$

Based on Equation 11, the evolution of the laser light intensity was taken as

$$
I_{b} \propto I_{0} \exp (-\bar{\alpha} \cdot x)
$$

where

$$
\bar{\alpha}=\overline{\sum N_{i} \cdot \sigma_{i}}
$$

is the average extinction coefficient, $\bar{\alpha} \simeq 1.43 \mathrm{~cm}^{-1}$ for this case. The LIF intensity obtained with the simple model is in close agreement with the LIF intensity calculated with the full model. The implications of this agreement are that the fine details of the spectrally selective quenching and absorption processes are secondary to basic features of the $\mathrm{OH}$ fluorescence process. These basic features are the proportionality of the fluorescence intensity on $\mathrm{OH}$ concentration and laser intensity. In turn, the laser intensity strongly decreases with distance due to the absorption of the light by the $\mathrm{OH}$ molecules. In the downstream portion of the reaction zone where absorption is important, the $\mathrm{OH}$ concentration is sufficiently independent of distance that the absorption coefficient can be adequately represented as a constant.

\subsection{2-D simulation results}

An automatic procedure has been used to obtain reduced reaction schemes starting from the full model of Mével. Details about this procedure can be found in Refs. $[39,63]$. The reduction process used the following error acceptance criteria: (i) $1 \%$ for the time to peak thermicity, (ii) $5 \%$ for the maximum thermicity, (iii) $20 \mathrm{~K}$ for 
the temperature profile, and (iv) $1 \%$ for the molar mass profile. The thermicity, $\dot{\Sigma}$, corresponds to the normalized energy release rate and is defined as [64]

$$
\dot{\Sigma}=\frac{1}{\rho} \sum_{i=1}^{N b_{i}}\left(\frac{\bar{M}_{m}}{M_{i}}-\frac{h_{i}}{C_{P} \cdot T}\right) \cdot \bar{\omega}_{i} .
$$

The reduction was performed for temperatures and pressures representative of a detonation propagating with a velocity ranging from 0.8 to $1.4 \mathrm{D}_{C J}$. For the Ar-diluted mixture, the reduced reaction model is composed of 17 reversible reactions and 9 species (including $\mathrm{Ar}$ ). For the $\mathrm{N}_{2}$-diluted mixture, the reduced reaction model is composed of 12 reversible reactions and 8 species. The reaction models are given in Table 1 and Table 2. Figure 10 compares the temperature and thermicity profiles in the ZND reaction zone, for a $\mathrm{N}_{2}$-diluted mixture, obtained with the detailed and reduced schemes. For both CJ and over-driven detonations, the reduction procedure results in an acceptable reduction in accuracy of the model predictions. Comparable results were found for Ar-diluted mixtures. Depending on the mixture considered, the computational time was reduced by a factor of up to 4 when the reduced model was used instead of the full model.

2-D simulations of detonations in a stoichiometric $\mathrm{H}_{2}-\mathrm{O}_{2}$ mixture with $\mathrm{X}_{A r}=0.8$ and $\mathrm{X}_{N 2}=0.6$ were performed using the numerical method described in subsection 2.1. The pressure dependencies of the 3-body reaction rates are taken into account within the simulation via either the Lindeman or Troe formalisms. The computational mesh finest spatial resolution was either 16 or $32 \mu \mathrm{m}$. Symmetry conditions were imposed on the upper and lower (perpendicular to the detonation propagation direction) boundaries. The width of the domain ranged from 13.6 to 20 $\mathrm{mm}$.

Figure 11 and Figure 12 compare the experimental and the numerical results. In each figure, schlieren, PLIF and superimposed schlieren-PLIF images are presented. Figure 11 has been obtained for a Ar-diluted mixture, which is an example of weakly unstable detonation with a reduced activation energy around 5, whereas Figure 12 has been obtained for a $\mathrm{N}_{2}$-diluted mixture representing a moderately unstable det- 
onation with a reduced activation energy around 6.5.

For both cases, reasonable agreement is observed for the overall features and many details for schlieren, OH PLIF and superimposed images. The observed spatial variations in the fluorescence image can clearly be directly linked to the varying $\mathrm{OH}$ concentrations created by the instability of the detonation front. In particular, the sharp onset and subsequent decay of the fluorescence signal are well predicted. The results also show that the vortex structures associated with Kelvin-Helmholtz instability of shear layer are indeed responsible for the vortex-like fluorescence images observed in the experiments $[28,29]$. The progressive attenuation of the LIF signal intensity due to the laser sheet absorption is particularly apparent in the center of Figure 12, where a dark strip can be seen in the LIF images. As observed in the experiments, the simulation of the $\mathrm{N}_{2}$-diluted mixture appears slightly more unstable than the Ar-diluted case.

Figure 13 shows a comparison between the simulated $\mathrm{OH}$ mass fraction and LIF intensity fields. The two images are quite different. The region of $\mathrm{OH}$ high concentration at the detonation front is much thicker than the region of high LIF intensity and the numerous pockets of high $\mathrm{OH}$ density located behind the detonation front do not appear in the LIF images. As mentioned previously, this is because a very large fraction of the laser light is absorbed just behind the detonation front by the layer of gas which contains a high $\mathrm{OH}$ radical concentration. These results show the difficulty of performing a quantitative analysis of $\mathrm{OH}$ radicals in a detonation front using the PLIF technique. They also show that the PLIF images can be misleading if the limitations of the diagnostic are not taken into account. Indeed, at first glance, the experimental LIF images would lead to the conclusion that high concentrations of $\mathrm{OH}$ radical are present only at the detonation front whereas the numerical simulations show numerous pockets of high $\mathrm{OH}$ density far downstream of the front. This difference is due to the significant amount of absorption of the incident laser associated with the large $\mathrm{OH}$ concentrations at the detonation front.

The ZND simulation results demonstrated that the propagation velocity is an important parameter in determining the LIF signal intensity. In order to investigate its effect on simulated PLIF intensity field, simulations were performed for a deto- 
nation propagating at a sub-Chapman-Jouguet velocity. The heat and momentum losses responsible for the velocity deficit were simulated by reducing the water vapor formation enthalpy. This method has been demonstrated previously as being convenient to account for small velocity deficits [63]. Figure 14 compares two simulated superimposed schlieren-PLIF images obtained for a detonation velocity of $\mathrm{D}_{C J}$ and $0.924 \mathrm{D}_{C J}$. From these results, the propagation velocity does not appear to significantly affect the qualitative appearance of the LIF intensity field. As expected, the cell size obtained with the imposed velocity deficit is much closer to the cell size measured in the experiment during which a comparable velocity deficit, about $8 \%$ for $80 \%$ Ar, was observed [28].

Additional improvements in the modeling can be made by accounting for the spatial distribution of the exciting laser sheet and the response characteristics of the imaging camera. The effect on the LIF intensity of these two parameters is illustrated in Figure 15. In Figure 15 b) a uniform laser sheet is used whereas in Figure 15 c), the laser sheet spatial distribution is assumed to be gaussian and a camera cutoff threshold set at $20 \%$ is added. A realistic spatial distribution shape was calculated based on the study of Thiery et al. [65]. The cutoff value used is based on an analysis of selected experimental LIF images. The spatial distribution of the laser sheet intensity is responsible for the asymmetric LIF intensity at the detonation front. Applying a threshold cutoff to account for the camera detection limit enables reproducing the dark areas behind the detonation front that are prominent in the experimental images.

\section{Discussion}

The results described in the previous section essentially demonstrate the good qualitative agreement between the experimental and calculated laser induced fluorescence intensities both for ZND profiles and 2-D simulations of detonation waves.

As described by Daily [59], a wide range of models with various degree of complexity can be used to model the LIF phenomenon. Despite its simplicity, a three-level model is well suited for most conditions encompassed in combustion studies [42]. 
In the conditions presently investigated, the three-level LIF model approach has proved able to predict accurately the LIF intensity. Although a more complex LIF model $[66,67,68]$ could have been implemented, because the absorption of the laser light is the dominant parameter controlling the LIF intensity, we found that a very simple LIF model with a Beer-Lambert absorption law could be used to described the main features observed in the experiments. Pintgen [30] performed a systematic parametric study of the LIF model applied to ZND simulations. Although the spectral configuration was slightly different, he also concluded that the absorption of the laser light was the dominant parameter controlling the LIF intensity. The agreement between the LIF intensities computed from Equation 1, full model, and Equation 15, simple model, indicates that the spectroscopic characteristics of the probed species, $\sigma_{O H}$, dominates over the laser characteristics, $\Gamma$ and $I_{\nu}^{0}$, and chemical environment, $Q$. The A and B Einstein coefficients are constant. The Bolzmann fraction varies by only about $10 \%$ behind the ZND front. The spectral laser irradiance, $I_{\nu}^{0}$, is a constant, whereas the integral overlap, $\Gamma$, which depends both on the laser and absorption line shapes, varies by only $20 \%$ behind the ZND front. The quenching rate exhibits larger variations, about a factor of 2, within the ZND profile. The LIF signal intensity depends on the $\mathrm{OH}$ radical number density in two distinct ways. The $\mathrm{OH}$ fluorescence intensity depends linearly on the concentration, $N_{O H}$, which grows exponentially within the reaction zone due to chain branching and then slowly approaches the equilibrium values at large distances from the front. The laser light intensity decreases exponentially with increasing $\mathrm{OH}$ concentration due to absorption (Beer-Lambert law). The linear dependence dominates in the initial part of the reaction zone in which the increase of $\mathrm{OH}$ is so rapid that the fluorescence signal appears to have a sharp front. The exponential decay dominates in the latter part of the reaction zone and creates the impression that the $\mathrm{OH}$ concentration decreases rapidly with increasing distance from the peak in fluorescence intensity. It is to note that the weak influence of the quenching rate variation is magnified in the present study because of the spectrally integrated nature of the experiment and the normalization step. This might not hold true for spectrally resolved LIF study which focus on the quantification of the probed species. 
Despite the satisfactory qualitative agreement between the experiments and the calculated LIF intensities derived from the computed ZND structures, the solutions are sensitive to a number of parameters. The most important parameters are the actual position and width of the laser line. The step width of the dye laser grating is $0.06 \mathrm{~cm}^{-1}$ whereas the effect of the laser center line position has been investigated using a shift of $0.2 \mathrm{~cm}^{-1}$. This higher value may account for the absorption line pressure-induced shift, estimated to range between -0.14 and $-0.07 \mathrm{~cm}^{-1}$, which was neglected in the model. The laser line width used in the model was $0.1 \mathrm{~cm}^{-1}$, of the order typically observed for the dye laser used in the experiments [30,37], but it is likely than the actual laser line width was higher. The combined effect of the laser line position and width would induce a faster decrease of the LIF signal intensity than calculated with the default parameter values used in the LIF model.

The other dominant parameter that influences the LIF signals is the detonation velocity. When considering the LIF signal obtained from the ZND simulations, two phenomena have to be taken into account: the velocity oscillation during a cellular cycle, and the velocity deficit. The ZND solution is usually obtained for the CJ detonation velocity whereas large oscillation velocity are observed within a cell cycle $[28,63,69,70]$. In order to extract reliable LIF data from the experiments, the image stripes analysed were located within the second half of the cell cycle so that the velocity is closed to the CJ detonation and the LIF field is not affected by 3-dimensional effects. However, the instantaneous front velocity is not known precisely. Moreover, velocity deficits around $8 \%$ for $2 \mathrm{H}_{2}-\mathrm{O}_{2}-12 \mathrm{Ar}$ mixtures, were recorded during the experiments performed in the narrow channel. Consequently, the actual velocity for the LIF images used is likely to be lower than the CJ velocity which leads to a significant uncertainty. Due to all these limitations with respect to the analysis based on the ZND model, 2-D simulations constitute a much more satisfactory framework to interpret the LIF images. 


\section{Conclusion}

In the present study, a laser induced fluorescence model has been applied for the first time to multi-dimensional detonation wave numerical simulation. The sensitivity of the results to the parameters of the LIF model were examined by comparing one-dimensional slices of experimental data to simulated LIF signals based on ZND model solutions. These results show that a three-level LIF model with some simplifying assumptions can quantitatively reproduce the shape of the observed LIF signals. The LIF model was then applied to the output of two-dimensional, unsteady detonation simulations based on a detailed, but reduced reaction mechanism. Based on comparison of synthetic and experimental PLIF images as well as detailed evaluation of the terms in the PLIF model, the dominant interference process has been determined to be the absorption of the incident laser sheet. This is due to the high concentration of $\mathrm{OH}$ radicals $(1-2 \%)$ downstream of the main reaction zone. Less dominant but also important are the effects of the quenching, incident laser lineshape modification due to absorption, and absorption of the emitted fluorescence (radiative trapping). The absorption of the incident laser sheet can be adequately described by Beer's law using an average absorption coefficient. Combining this with a simple linear fluorescence emission model provides a simple method of rapidly generating a synthetic PLIF image. Comparison of the predicted and observed LIF signals indicated that although the overall features of the observed LIF signals are well reproduced by the simulation, quantitative comparison is limited by a number of factors, particularly the nature of the experimental data, which are samples of unsteady process that by its very nature, cannot be synchronized precisely with the simulations. The most important limitation is that the strong absorption of the incident laser sheet results in a low signal-to-noise ratio except very near the front. This prevents us from examining the downstream region for the existence of "unburnt pockets" in a definitive fashion. The experiments also have some three-dimensional features while the simulations are two-dimensional.The present approach which combines fluid mechanics, chemistry and spectroscopic models, could constitute a useful tool to evaluate and design new experimental setup for detonation wave imaging. 


\section{Acknowledgements}

The authors wish to acknowledge Dr Laure Pillier, from PC2A-CNRS Lille, for usefull discussions about the LIF phenomenon. 2D detonation simulations were performed using computational resources of the EPEE Federation of the CNRS and University of Orléans and of the CCSC Computational Center of Région Centre. 


\section{References}

[1] M. Berthelot, P. Vieille, Ann. Chim. Phys. 28 (1883) 289-332.

[2] E. Mallard E., H. Le Chatelier, Ann. Mines 4 (1883) 274-568.

[3] B.V. Voitsekhovskii, Dokl. Akad. Nauk SSSR 114 (1957) 717-720.

[4] Y.N. Denisov, Y. K. Troshin, Dokl. Akad. Nauk SSSR 125 (1959) 110-113.

[5] Y.N. Denisov, Y. K. Troshin, Soviet Physics-Technical Physics 30 (1960) 450.

[6] D.L. Chapman, Philos. Mag. 47 (1899) 90-104.

[7] E. Jouguet, J. Math. Pures Appl. 1 (1905) 347-425.

[8] Y.B. Zel'dovich, J. Exp. Theor. Phys. 10 (1940) 543-568.

[9] J. von Neumann, Theory of detonation waves, Pergamon, 1942.

[10] W. Doering, Ann. Phys. 43 (1943) 421-436.

[11] R. Strehlow, Acta Astronaut. 14 (1969) 539-548.

[12] J.C. Libouton, A. Jacques, P.J. Van Tiggelen, Cinétique, structure et entretien des ondes de détonation. Colloque International Berthelot-Vieille-Mallard-Le Chatelier 2 (1981) 437-442.

[13] H. Presles, D. Desbordes, M. Guirard, C. Guerraud, Shock Waves 6 (1996) 111-114.

[14] A.K. Oppenheim, R.I. Soloukhin, Annu. Rev. Fluid Mech. 5 (1973) 31-58.

[15] J.H.S. Lee, Annu. Rev. Fluid Mech. 16 (1984) 311-336.

[16] H.N. Presles, D. Desbordes, P. Bauer, Combust. Flame 70 (1987) 207-213.

[17] D. R. White, Phys. Fluids 4 (1961) 465-480.

[18] D. R. White, G. E. Moore, Proc. Combust. Inst. 10 (1965) 785-795. 
[19] B.V. Voitsekhovskii, V.V. Mitrofanov, M.E.. Topchian, Fiz Goren Vzryva 5 (1969) 385-395.

[20] J. H. S. Lee, The Detonation Phenomenon, Cambridge University Press, 2008

[21] A. K. Oppenheim, P. A. Urtiew, F. J. Weinberg, P. Roy. Soc. Lond. A Mat. 291 (1966) 279-290.

[22] P. A. Urtiew, A. K. Oppenheim, P. Roy. Soc. Lond. A Mat. 295 (1966) 13-28.

[23] R. I. Soloukhin, Shock waves and detonation in gases, Fizmatgiz, 1963.

[24] A.K. Oppenheim, Philos. Trans. R. Soc. Lond., A 315 (1985) 471-508.

[25] T. Anderson, E. Dabora, Proc. Combust. Inst. 24 (1992) 1853-1860.

[26] M. Kamel, C. Morris, I. Stouklov, R. Hanson, Proc. Combust. Inst. 26 (1996) 2909-2915.

[27] C. Viguier, A. Gourara, D. Desbordes, Proc. Combust. Inst. 27 (1998) 22072214 .

[28] J. M. Austin, The role of instability in gaseous detonation, Ph.D. thesis, California Institute of Technology, 2003.

[29] J. M. Austin, F. Pintgen, J. E. Shepherd, Proc. Combust. Inst. 30 (2005) 18491857.

[30] F. Pintgen, Laser-optical visualization of detonation structures., Master's thesis, Technische Universitat Munchen-California Institute of Technology, 2000.

[31] F. Pintgen, C. A. Eckett, J. M. Austin, J. E. Shepherd, Combust. Flame 133 (2003) 211-229.

[32] F. Pintgen, J. E. Shepherd, Combust. Flame 156 (2009) 655-677.

[33] F. Pintgen, J. E. Shepherd, Quantitative analysis of reaction front geometry in detonation, International colloquium on application of detonation for propulsion (2004) 23-28. 
[34] G. Wang, C. Ma, B. Wang, Q.Z. Lin, Chin. Sci. Bull. 54 (2009) 2247-2255.

[35] A. M. Khokhlov, J. M. Austin, F. Pintgen, J. E. Shepherd, Numerical study of the detonation wave structure in ethylene-oxygen mixtures, $42^{\text {th }}$ AIAA Aerospace Sciences Meeting and Exhibit (2004).

[36] Z. Liang, S. Browne, R. Deiterding, J. E. Shepherd, Proc. Combust. Inst. 31 (2007) 2445-2453.

[37] F. Pintgen, Detonation diffraction in mixtures with various degrees of instability, Ph.D. thesis, California Institute of Technology, 2004.

[38] S. Kao, J. E. Shepherd, Numerical solution methods for control volume explosions and ZND detonation structure, Technical Report FM2006.007, GALCIT, 2008.

[39] D. Davidenko, R. Mével, G. Dupré, Shock Waves 21 (2011) 85-99.

[40] G.-S. Jiang, C.-W. Shu, J. Comput. Phys. 126 (1996) 202-228.

[41] X. Zhong, J. Comput. Phys. 128 (1996) 19-31.

[42] G. Bessler, C. Schulz, V. Sick, J. Daily, A versatile modeling tool for nitric oxide LIF spectra, Proceedings of the Third Joint Meeting of the U.S. Sections of the Combustion Institute (2003).

[43] C. Eckbreth, Laser Diagnostics for Combustion Temperature and Species, Gordon and Breach, 1996.

[44] L. Rothman, A. Barbe, D. Benner, L. Brown, C. Camy-Peyret, M. Carleer, K. Chance, C. Clerbaux, V. Dana, V. Devi, A. Fayt, J.-M. Flaud, R. Gamache, A. Goldman, D. Jacquemart, K. Jucks, W. Lafferty, J.-Y. Mandin, S. Massie, V. Nemtchinov, D. Newnham, A. Perrin, C. Rinsland, J. Schroeder, K. Smith, M. Smith, K. Tang, R. Toth, J. Vander Auwera, P. Varanasi, K. Yoshino, J. Quant. Spectrosc. Ra. 82 (2003) 5-44.

[45] W. Partridge, N. Laurendeau, Appl. Optics 34 (1995) 2645-2647. 
[46] T. Ida, M. Ando, H. Toraya, J. Appl. Crystallogr. 33 (2000) 1311-1316.

[47] E. Rea, A. Chang, R. Hanson, J. Quant. Spectrosc. Ra. 37 (1987) 117-127.

[48] E. Rea, A. Chang, R. Hanson, J. Quant. Spectrosc. Ra. 41 (1989) 29-42.

[49] B. Shirinzadeh, D. Bakalyar, C. Wang, J. Chem. Phys. 82 (1985) 2877-2890.

[50] S. M. Hwang, J. N. Kojima, Q.-V. Nguyen, M. J. Rabinowitz, J. Quant. Spectrosc. Ra. 109 (2008) 2715-2724.

[51] W. Kessler, M. Allen, S. Davis, J. Quant. Spectrosc. Ra. 47 (1993) 107-117.

[52] C. Schulz, J. Jeffries, D. Davidson, J. Koch, J. Wolfrum, R. Hanson, Proc. Combust. Inst. 29 (2002) 2735-2742.

[53] P. Paul, J. Quant. Spectrosc. Ra. 51 (1994) 511-524.

[54] H. Lin, M. Seaver, K. Tang, A. Knight, C. Parmenter, J. Chem. Phys. 70 (1979) $5442-5457$.

[55] M. Tamura, P. Berg, J. Harrington, J. Luque, J. Jeffries, G. Smith, D. Crosley, Combust. Flame 114 (1998) 502-514.

[56] P. Paul, J. Durant, J. Gray, M. Furlanetto, J. Chem. Phys. 102 (1995) 83788384.

[57] J. Luque, D. Crosley, LIFBASE: Database and spectral simulation (version 1.5), Technical Report MP 99-009, SRI, 1999.

[58] S. I. Jackson, J. M. Austin, J. E. Shepherd, AIAA J. 44 (2006) 2422-2425.

[59] J. W. Daily, Prog. Energy Combust. Sci. 23 (1997) 133-199.

[60] J. E. Shepherd, Progr. Astronaut. Aeronaut. 106 (1986) 263-293.

[61] R. Mével, S. Javoy, F. Lafosse, N. Chaumeix, G. Dupré, C.-E. Paillard, Proc. Combust. Inst. 32 (2009) 359-366.

[62] R. Mével, S. Javoy, G. Dupré, Proc. Combust. Inst. 33 (2011) 485-492. 
[63] R. Mével, Etude de mécanismes cinétiques et des propriétés explosives des mélanges hydrogène-protoxyde d'azote et silane-protoxyde d'azote. Application à la sécurité industrielle, Ph.D. thesis, Université d'Orléans, 2009.

[64] W. Fickett, W.C. Davis Detonation, University of California Press, 1979.

[65] L. Thiery, J. P. Prenel, R. Porcar, Opt. Commun. 123 (1996) 801-809.

[66] J. W. Daily, W. G. Bessler, C. Schulz, V. Sick, T.B. Settersten, AIAA Journal 43 (2005) 458-464.

[67] M. J. Dunn, Finite-rate chemistry effects in turbulent premixed combustion, Ph.D. thesis, The University of Sydney, 2008.

[68] M. J. Dunn, A. R. Masri, Appl. Phys. B 101 (2010) 445-463.

[69] V. N. Gamezo, D. Desbordes, E. S. Oran, Combust. Flame 116 (1999) 154-165.

[70] P. J. Van Tiggelen, J. C. Libouton, Ann. Phys-Paris 14 (1989) 649-660.

[71] W. Tsang, R. F. Hampson, J. Phys. Chem. Ref. Data 15 (1986) 1087-1280.

[72] A. A. Konnov, Detailed reaction mechanism for small hydrocarbons combustion. release 0.5., 2000.

[73] J. W. Sutherland, J. V. Michael, A. N. Pirraglia, F. L. Nesbitt, R. B. Klemm, Proc. Combust. Inst. 21 (1988) 929-941.

[74] A. N. Pirraglia, J. V. Michael, J. W. Sutherland, R. B. Klemm, J. Phys. Chem. 93 (1989) 282-291.

[75] M. Mueller, R. Yetter, F. Dryer, Proc. Combust. Inst. 21 (1998) 177-184.

[76] M. T. Allen, R. A. Yetter, F. L. Dryer, Combust. Flame 112 (1998) 302-311.

[77] J. V. Michael, J. W. Sutherland, J. Phys. Chem. 92 (1988) 3853-3857.

[78] J. W. Sutherland, P. M. Patterson, R. B. Klemm, Proc. Combust. Inst. 23 (1991) 51-57. 
[79] L. Brouwer, C. J. Cobos, J. Troe, H.-R. Dubal, F. Crim, J. Chem. Phys. 86 (1987) 6171-6182.

[80] M. A. Mueller, T. J. Kim, R. A. Yetter, F. L. Dryer, Int. J. Chem. Kinet. 31 (1999) 133-125.

[81] H. Hippler, J. Troe, Chem. Phys. Lett. 192 (1995) 333-337.

[82] L. F. Keyser, J. Phys. Chem. 92 (1995) 1193-1200. 


\section{Figure captions}

1 Schematic of the three-energy-level laser induced fluorescence model . 33

2 Spectral distribution of the laser line and the two absorption lines,

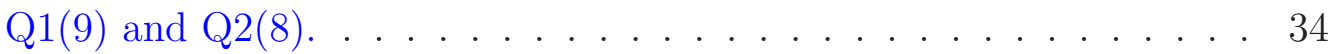

3 Schematic of the experimental setup for acquiring simultaneous schlieren and PLIF images $[30,37] \ldots \ldots . \ldots . \ldots . \ldots . \ldots 35$

4 Simultaneous schlieren and $\mathrm{OH}$ PLIF images of a detonation wave propagating in a $2 \mathrm{H}_{2}-\mathrm{O}_{2}-12 \mathrm{Ar}$ mixture [28]. Initial conditions: $\Phi=1$; $\mathrm{X}_{A r}=0.8 ; \mathrm{T}_{1}=295 \mathrm{~K}$ and $\mathrm{P}_{1}=20 \mathrm{kPa}$. a): schlieren image. b): $\mathrm{OH}$ PLIF image. c): Superimposed schlieren and PLIF images. PLIF image height is $60 \mathrm{~mm} \ldots \ldots \ldots$. . . . . . . . . . . . 36

5 (a) Comparison of the experimental [28] and calculated normalized LIF intensities for a $2 \mathrm{H}_{2}-\mathrm{O}_{2}-12 \mathrm{Ar}$ mixture. (b) Corresponding temperature and pressure profiles from ZND simulation. Initial conditions: $\Phi=1 ; \mathrm{X}_{A r}=0.8 ; \mathrm{T}_{1}=295 \mathrm{~K}$ and $\mathrm{P}_{1}=20 \mathrm{kPa} \ldots \ldots . . . . .37$

6 (a) Comparison of the experimental [37] and calculated normalized LIF intensities for a $2 \mathrm{H}_{2}-\mathrm{O}_{2}-5.5 \mathrm{~N}_{2}$ mixture. (b) Corresponding temperature and pressure profiles from ZND simulation. Initial conditions: $\Phi=1 ; \mathrm{X}_{N 2}=0.65 ; \mathrm{T}_{1}=295 \mathrm{~K}$ and $\mathrm{P}_{1}=20 \mathrm{kPa} \ldots \ldots . . . .38$

$7 \quad$ Evolution of the spectrally resolved normalized laser intensity as a function of distance behind the shock of a ZND detonation model for a $2 \mathrm{H}_{2}-\mathrm{O}_{2}-12 \mathrm{Ar}$ mixture. Initial conditions: $\Phi=1 ; \mathrm{X}_{A r}=0.8 ; \mathrm{T}_{1}=295$ $\mathrm{K}$ and $\mathrm{P}_{1}=20 \mathrm{kPa} \ldots \ldots \ldots \ldots \ldots \ldots$

8 Effect of the spectral configuration, laser line width and position, on the evolution of the normalized laser intensity with distance behind the shock of a ZND detonation model for a $2 \mathrm{H}_{2}-\mathrm{O}_{2}-12 \mathrm{Ar}$ mixture. Lines represent iso-contours of normalized incident light intensity. Initial conditions: $\Phi=1 ; \mathrm{X}_{A r}=0.8 ; \mathrm{T}_{1}=295 \mathrm{~K}$ and $\mathrm{P}_{1}=20 \mathrm{kPa}$. (a): laser line width increased from 0.1 to $1 \mathrm{~cm}^{-1}$. (b): laser center line shifted by $0.14 \mathrm{~cm}^{-1}$ (from 284.0065 to $\left.284.0053 \mathrm{~nm}\right) \ldots$. . . . . . . . . . . . 40 
9 Comparison of the experimental [28] and calculated (ZND model) normalized LIF intensities with the full, Equation 1, and simple, Equation 15, LIF models for a $2 \mathrm{H}_{2}-\mathrm{O}_{2}-12 \mathrm{Ar}$ mixture. ZND simulation. Initial conditions: $\Phi=1 ; \mathrm{X}_{A r}=0.8 ; \mathrm{T}_{1}=295 \mathrm{~K}$ and $\mathrm{P}_{1}=20 \mathrm{kPa} \ldots \ldots 41$

10 Thermicity and temperature profiles: comparison between the detailed and reduced kinetic scheme for a $2 \mathrm{H}_{2}-\mathrm{O}_{2}-4.5 \mathrm{~N}_{2}$ mixture. ZND reactor. Initial conditions: $\Phi=1 ; \mathrm{X}_{N 2}=0.6 ; \mathrm{T}_{1}=295 \mathrm{~K}$ and $\mathrm{P}_{1}=20 \mathrm{kPa} .42$

11 Comparison of experimental [28] (top) and numerical (bottom) images of a detonation wave propagating in a $2 \mathrm{H}_{2}-\mathrm{O}_{2}-12 \mathrm{Ar}$ mixture. Initial conditions: $\Phi=1 ; \mathrm{X}_{A r}=0.8 ; \mathrm{T}_{1}=295 \mathrm{~K}$ and $\mathrm{P}_{1}=20 \mathrm{kPa}$. a), d): schlieren images. b), e): OH PLIF images. c), f): superimposed schlieren and PLIF images. Experimental PLIF image height is 60 mm. Simulations were obtained in a $13.6 \mathrm{~mm}$ wide channel. . . . . . 43

12 Comparison of experimental [28] (top) and numerical (bottom) images of a detonation wave propagating in a $2 \mathrm{H}_{2}-\mathrm{O}_{2}-4.5 \mathrm{~N}_{2}$ mixture. Initial conditions: $\Phi=1 ; \mathrm{X}_{N 2}=0.6 ; \mathrm{T}_{1}=295 \mathrm{~K}$ and $\mathrm{P}_{1}=20 \mathrm{kPa}$. a), d): schlieren images. b), e): OH PLIF images. c), f): superimposed schlieren and PLIF images. Experimental PLIF image height is 30 mm. Simulations were obtained in a $20 \mathrm{~mm}$ wide channel. . . . . . . 44

13 Comparison of simulated schlieren-OH mass fraction field and schlierenPLIF image for a detonation wave propagating in a $2 \mathrm{H}_{2}-\mathrm{O}_{2}-12 \mathrm{Ar}$ mixture (top) and in a $2 \mathrm{H}_{2}-\mathrm{O}_{2}-4.5 \mathrm{~N}_{2}$ mixture (bottom). Initial conditions: Ar-diluted mixture: $\Phi=1 ; \mathrm{X}_{A r}=0.8 ; \mathrm{T}_{1}=295 \mathrm{~K}$ and $\mathrm{P}_{1}=20$ kPa. $\mathrm{N}_{2}$-diluted mixture: $\Phi=1 ; \mathrm{X}_{N 2}=0.6 ; \mathrm{T}_{1}=295 \mathrm{~K}$ and $\mathrm{P}_{1}=20 \mathrm{kPa}$. a) and c): superimposed schlieren and $\mathrm{OH}$ mass fraction field. b) and d): superimposed schlieren and PLIF images. Simulations were obtained in $13.6 \mathrm{~mm}$ (Ar-dulited mixture) and $20 \mathrm{~mm}\left(\mathrm{~N}_{2}\right.$-diluted mixture) wide channels. 
14 Comparison of simulated superimposed schlieren-PLIF images for detonation waves propagating with different velocity in a $2 \mathrm{H}_{2}-\mathrm{O}_{2}-12 \mathrm{Ar}$ mixture. Initial conditions: $\Phi=1 ; \mathrm{X}_{A r}=0.8 ; \mathrm{T}_{1}=295 \mathrm{~K}$ and $\mathrm{P}_{1}=20$ $\mathrm{kPa}$. a): $\mathrm{D} / \mathrm{D}_{C J}=1$. b): $\mathrm{D} / \mathrm{D}_{C J}=0.924$. Simulations were obtained in $13.6 \mathrm{~mm}\left(\mathrm{D} / \mathrm{D}_{C J}=1\right)$ and $20 \mathrm{~mm}\left(\mathrm{D} / \mathrm{D}_{C J}=0.924\right)$ wide channels. . 46

15 Effects of laser sheet intensity spatial distribution and camera detection limit on the simulated superimposed schlieren-PLIF images for detonation waves propagating in a $2 \mathrm{H}_{2}-\mathrm{O}_{2}-12 \mathrm{Ar}$ mixture. Initial conditions: $\Phi=1 ; \mathrm{X}_{A r}=0.8 ; \mathrm{T}_{1}=295 \mathrm{~K}$ and $\mathrm{P}_{1}=20 \mathrm{kPa}$. a): experimental. b): uniform laser intensity. c): gaussian laser intensity spatial distribution and camera cutoff threshold at $20 \%$. . . . . . . . . . 47 


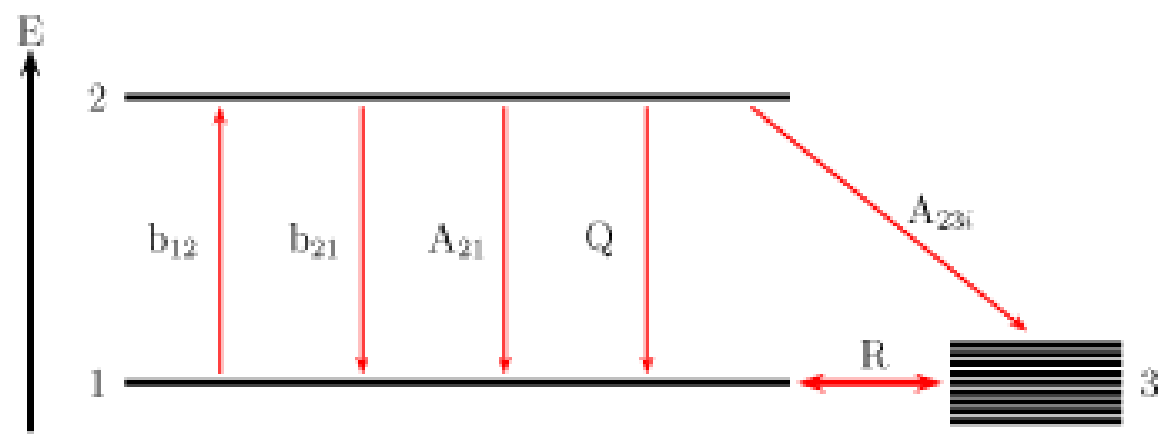

Figure 1: 


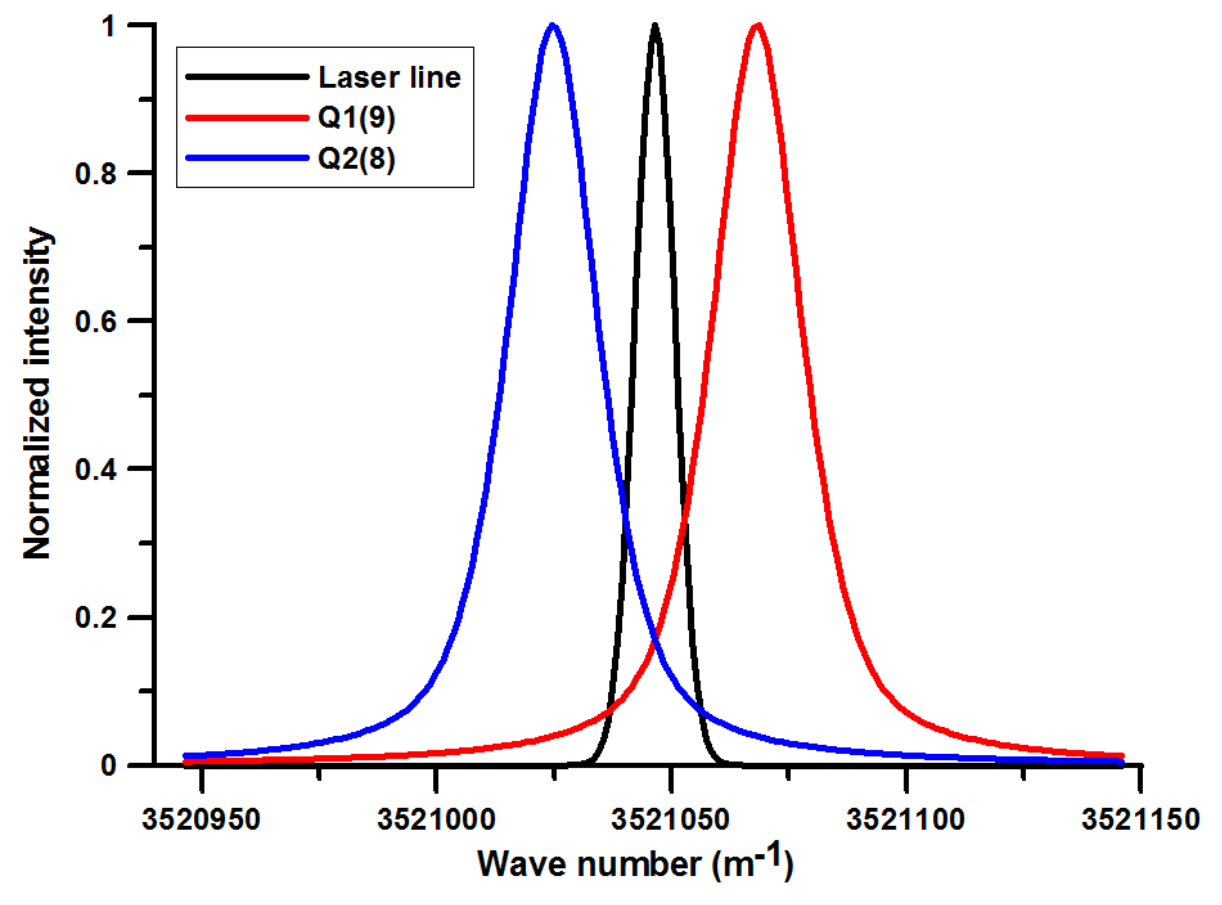

Figure 2: 


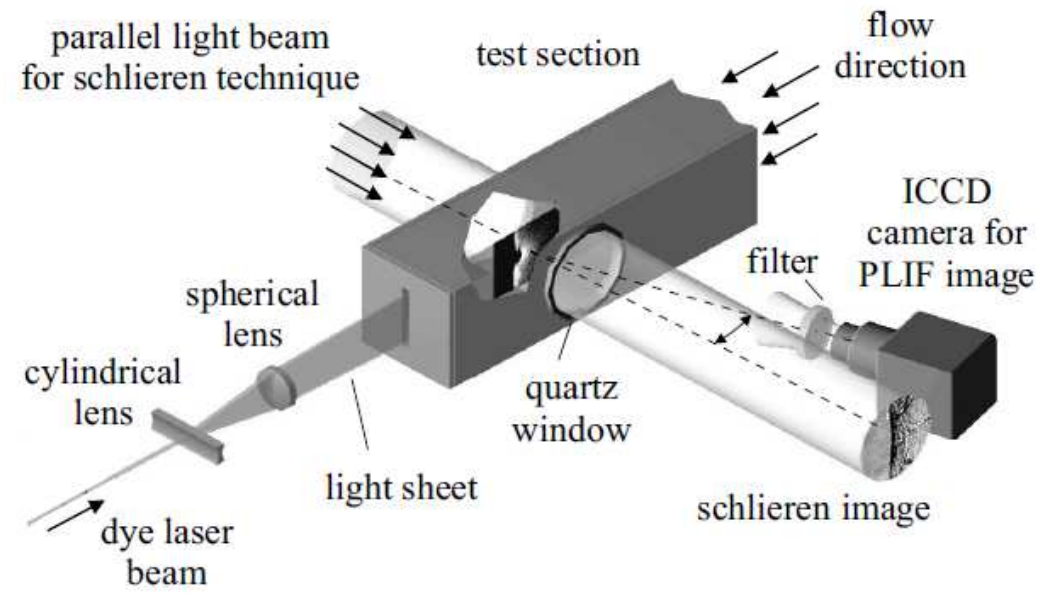

Figure 3: 


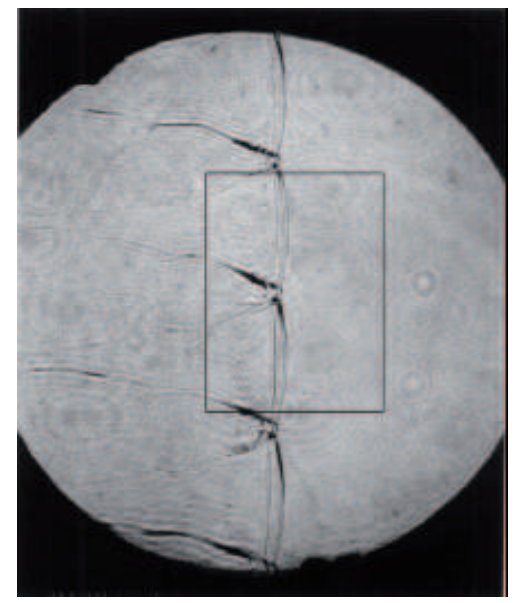

(a) schlieren

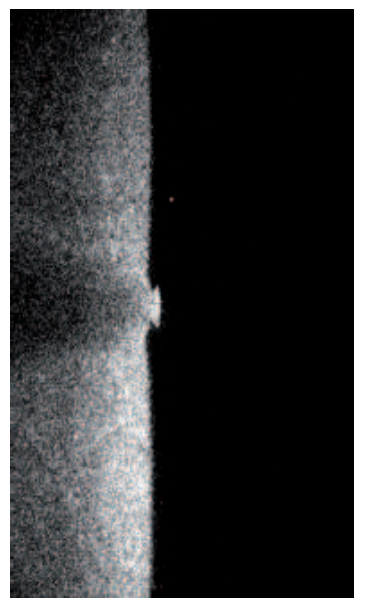

(b) OH PLIF

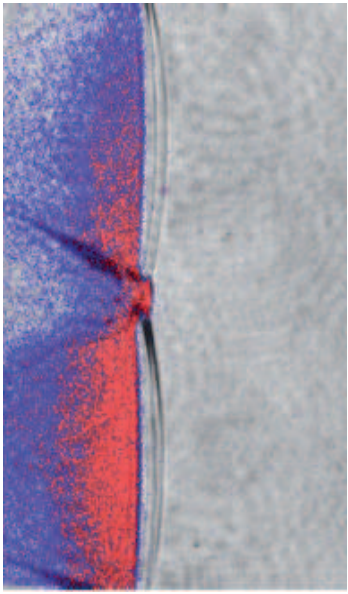

(c) Superimposed

Figure 4: 


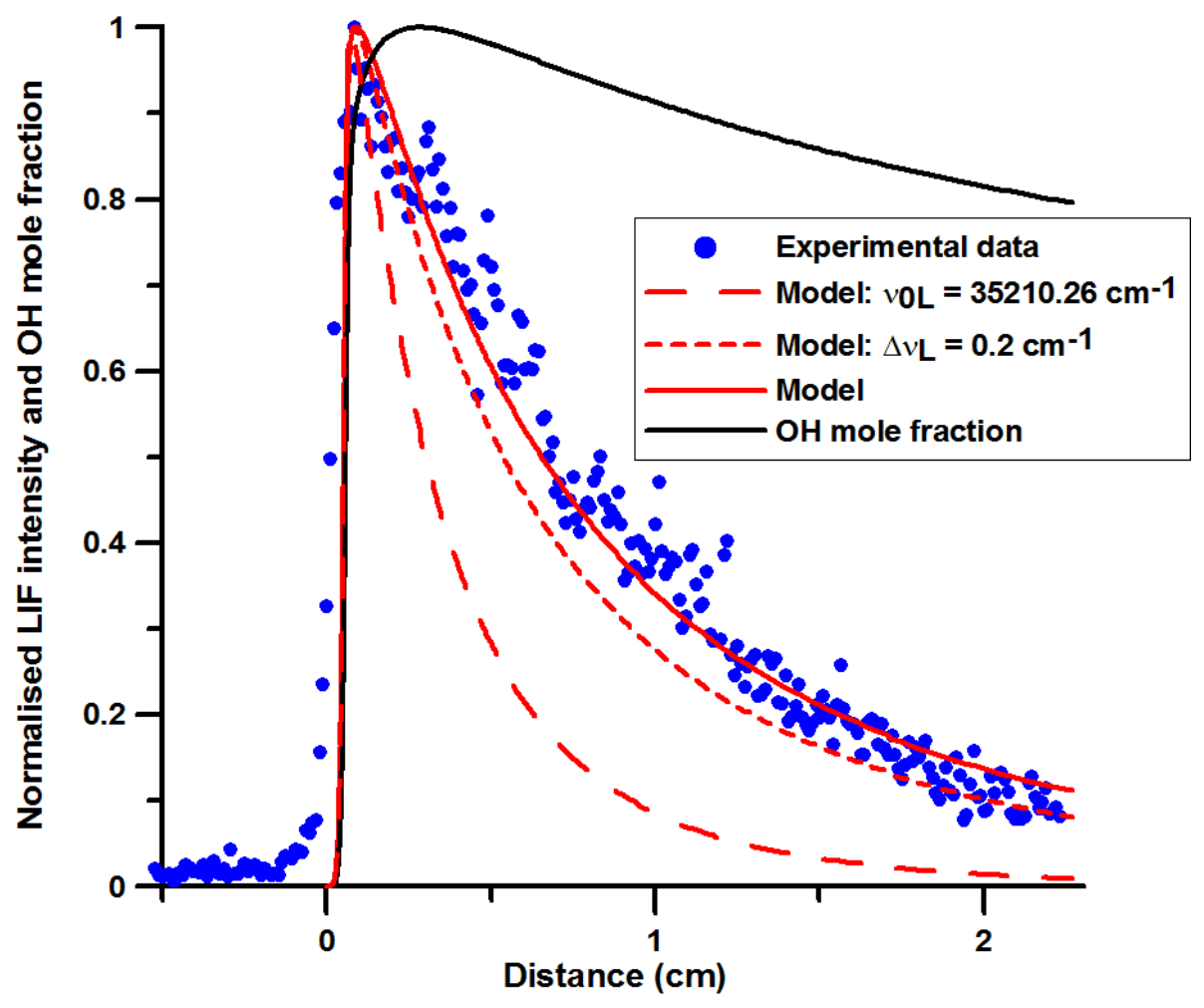

(a)

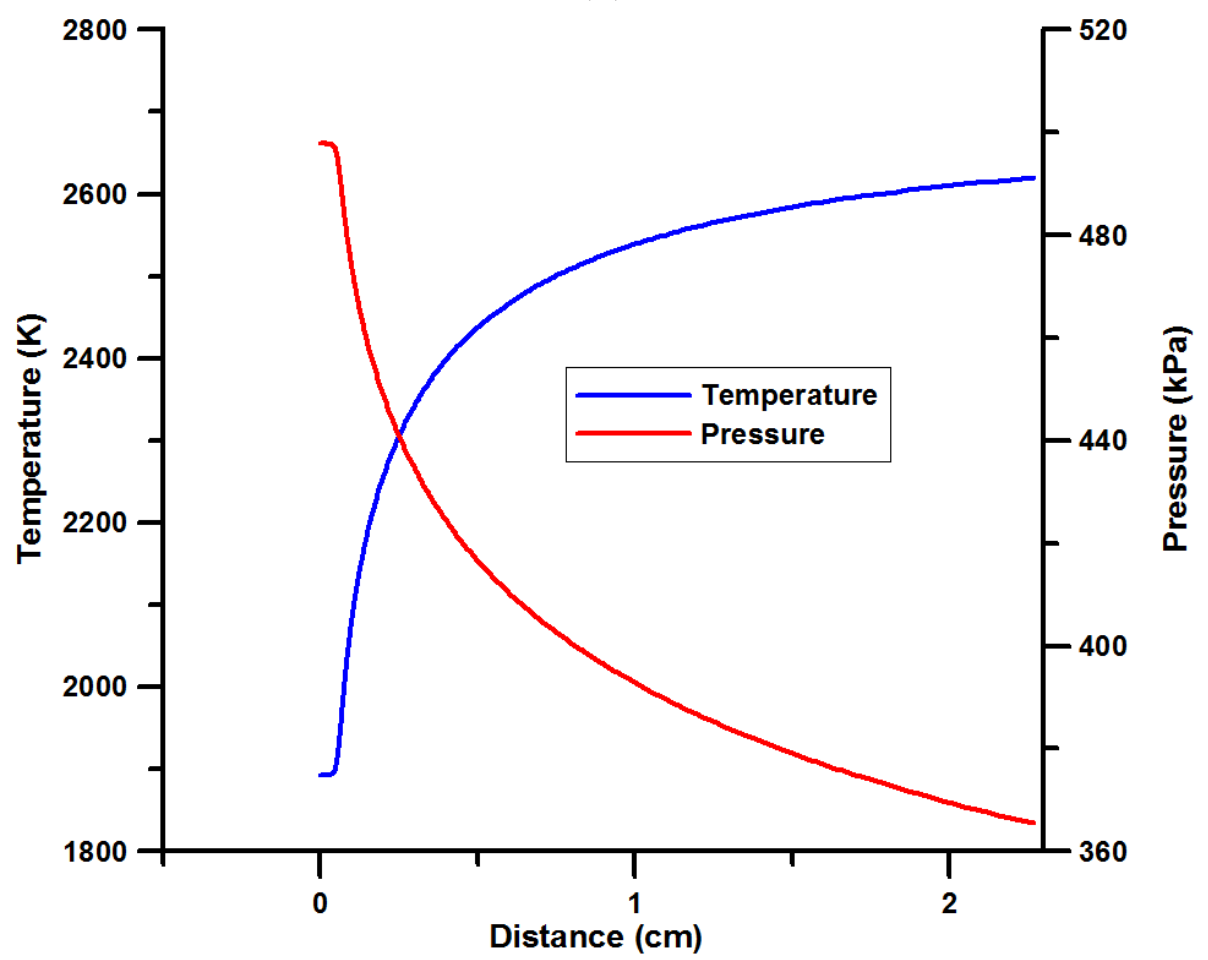

(b)

Figure 5: 


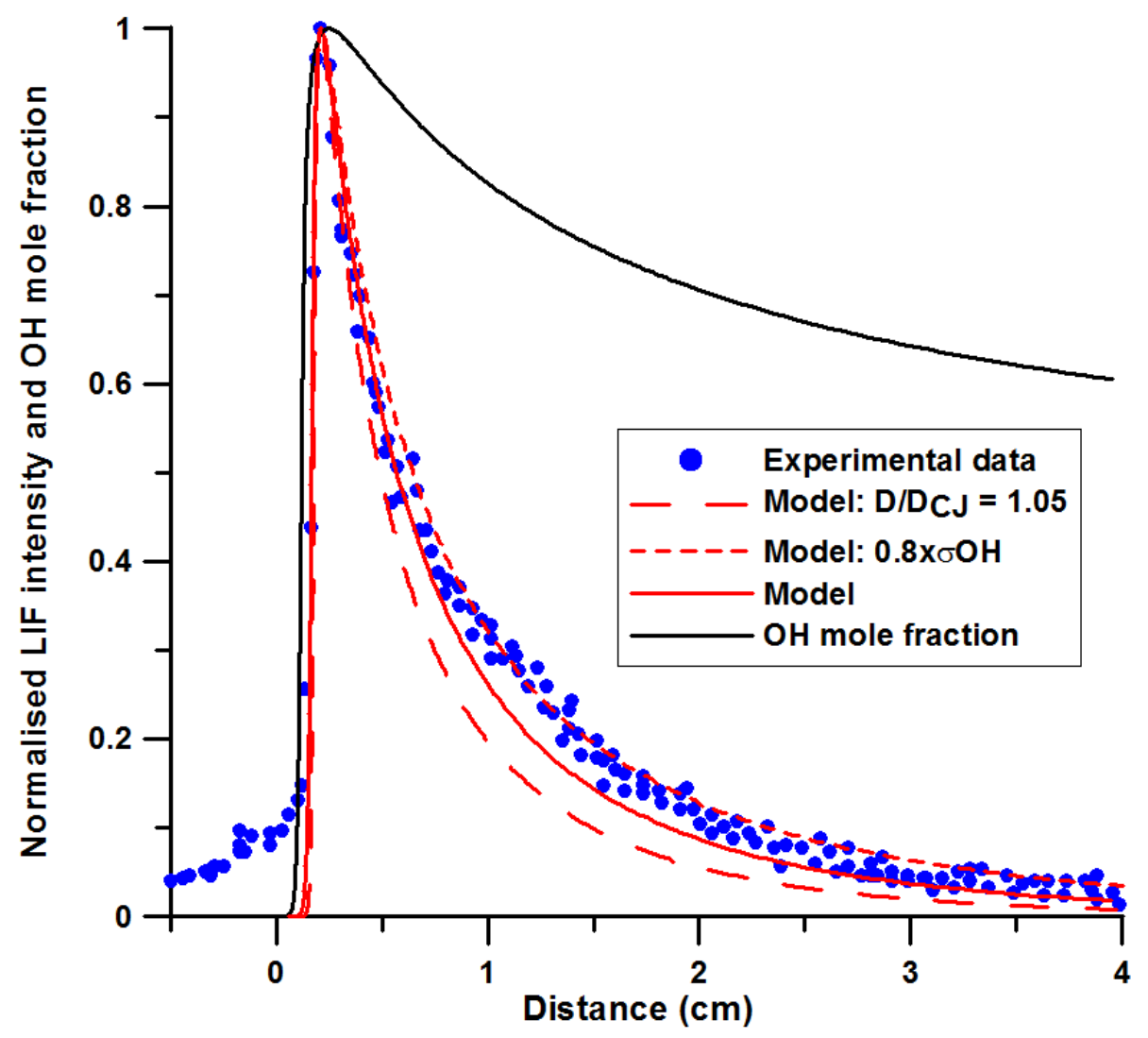

(a)

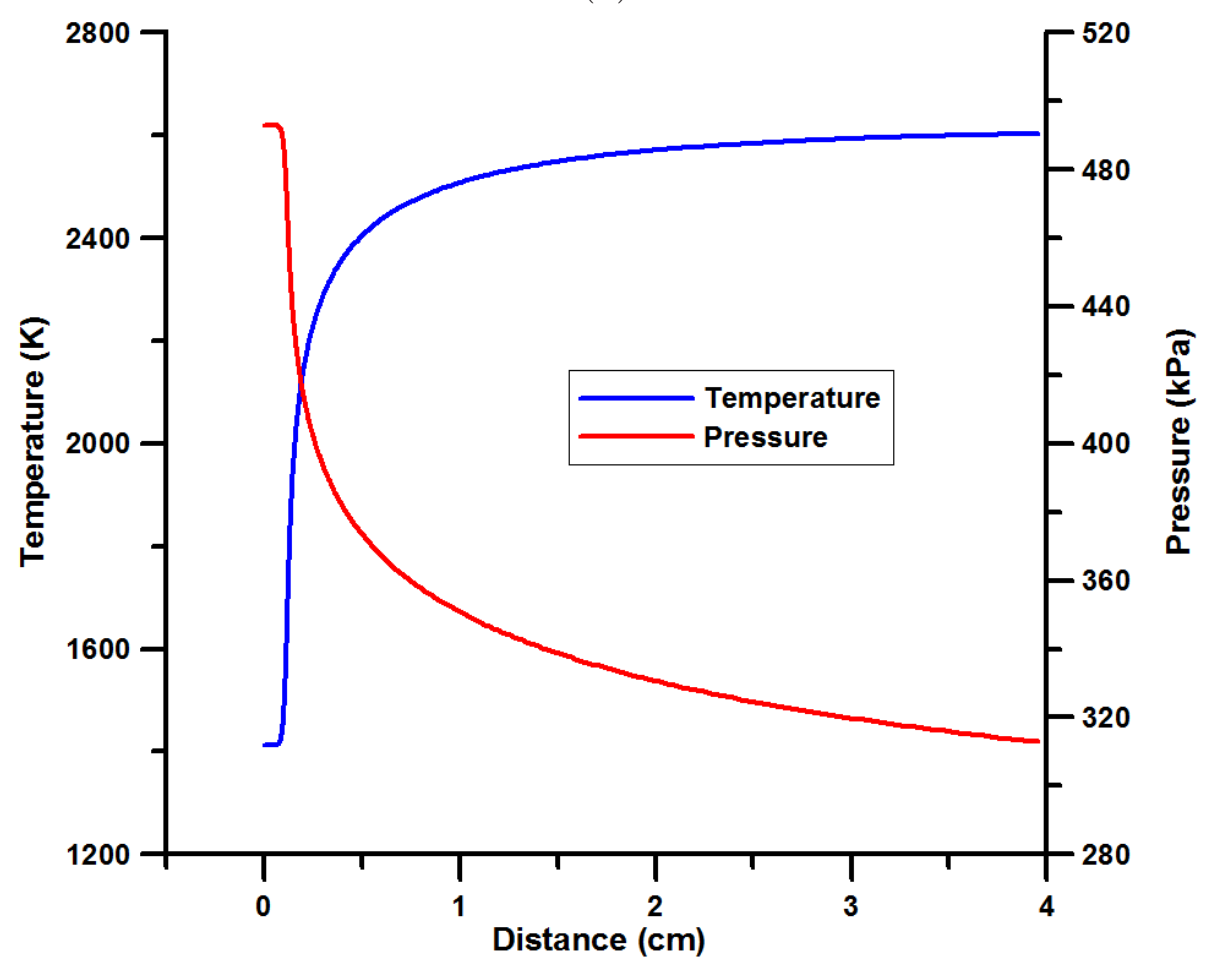

(b)

Figure 6: 


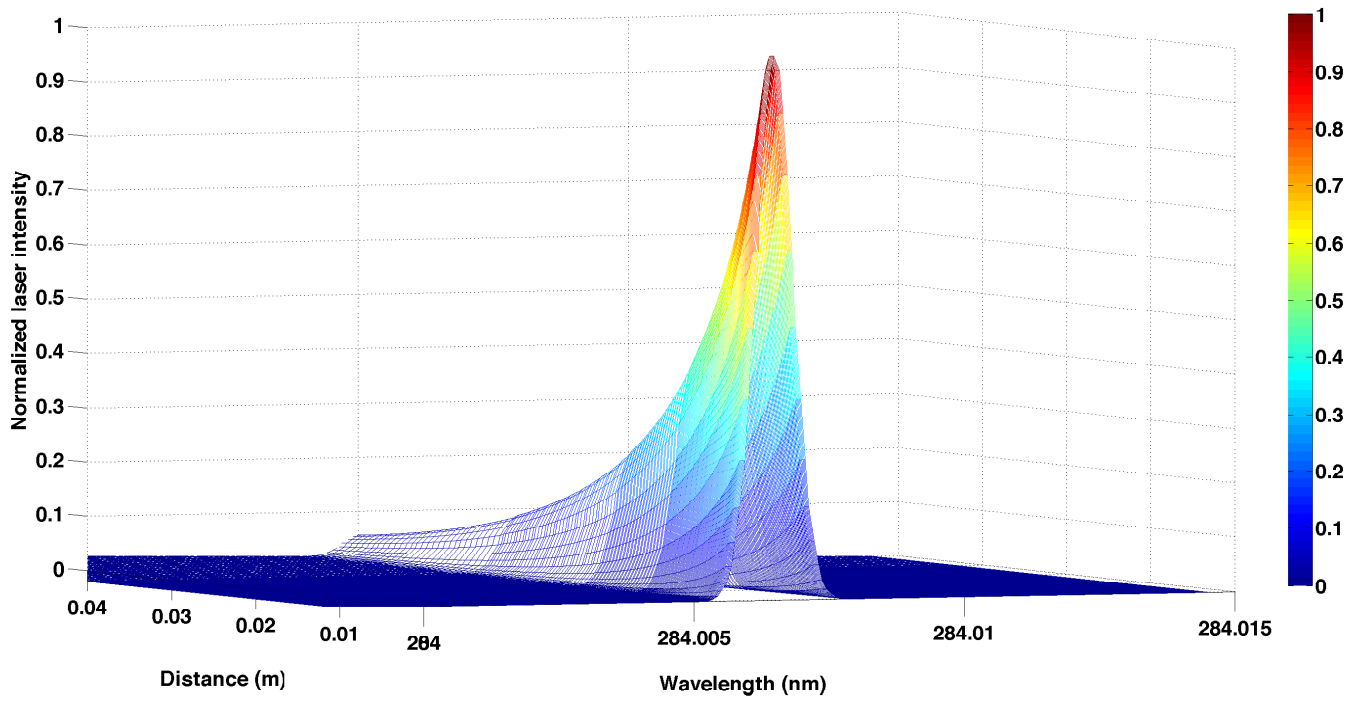

Figure 7: 


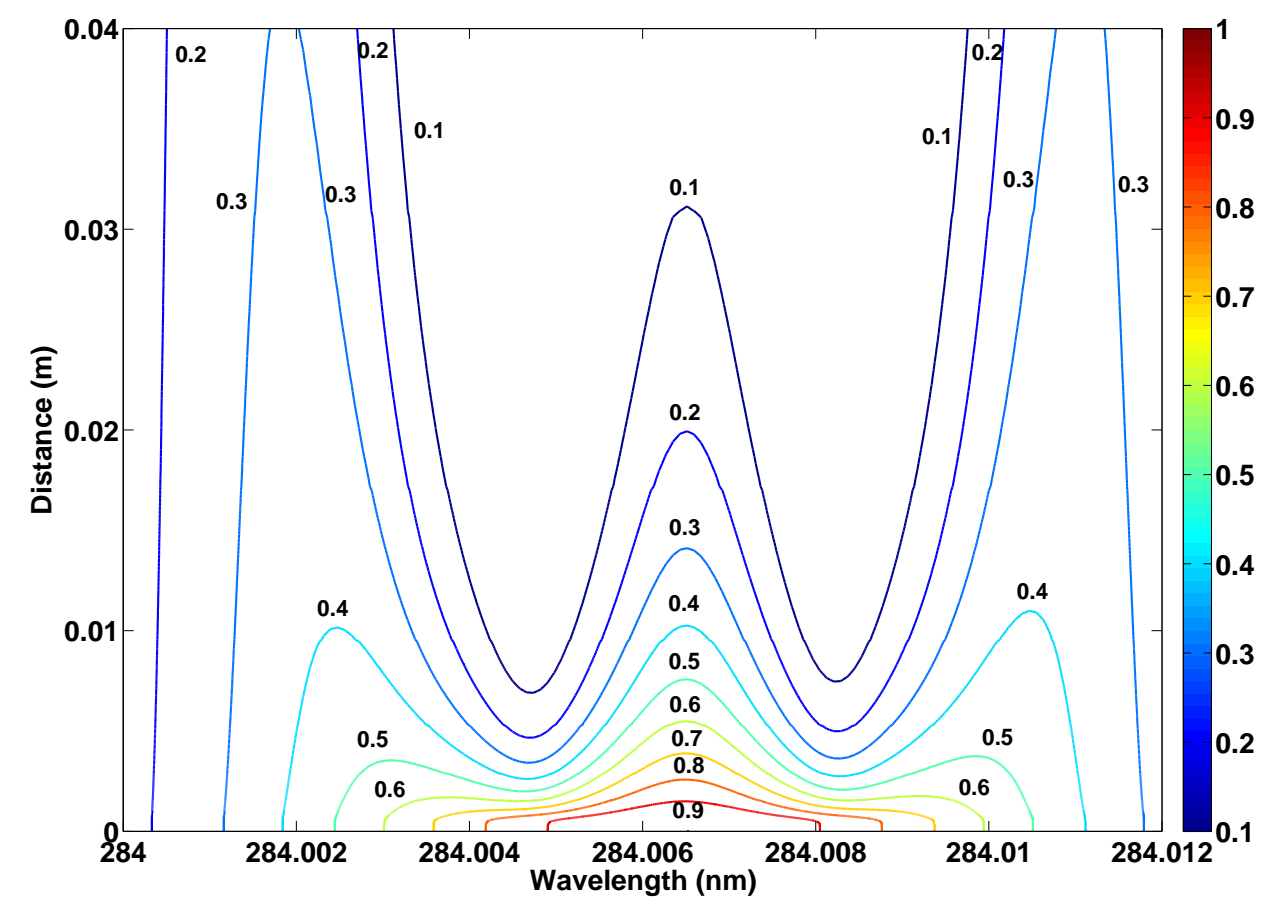

(a) effect of laser line width

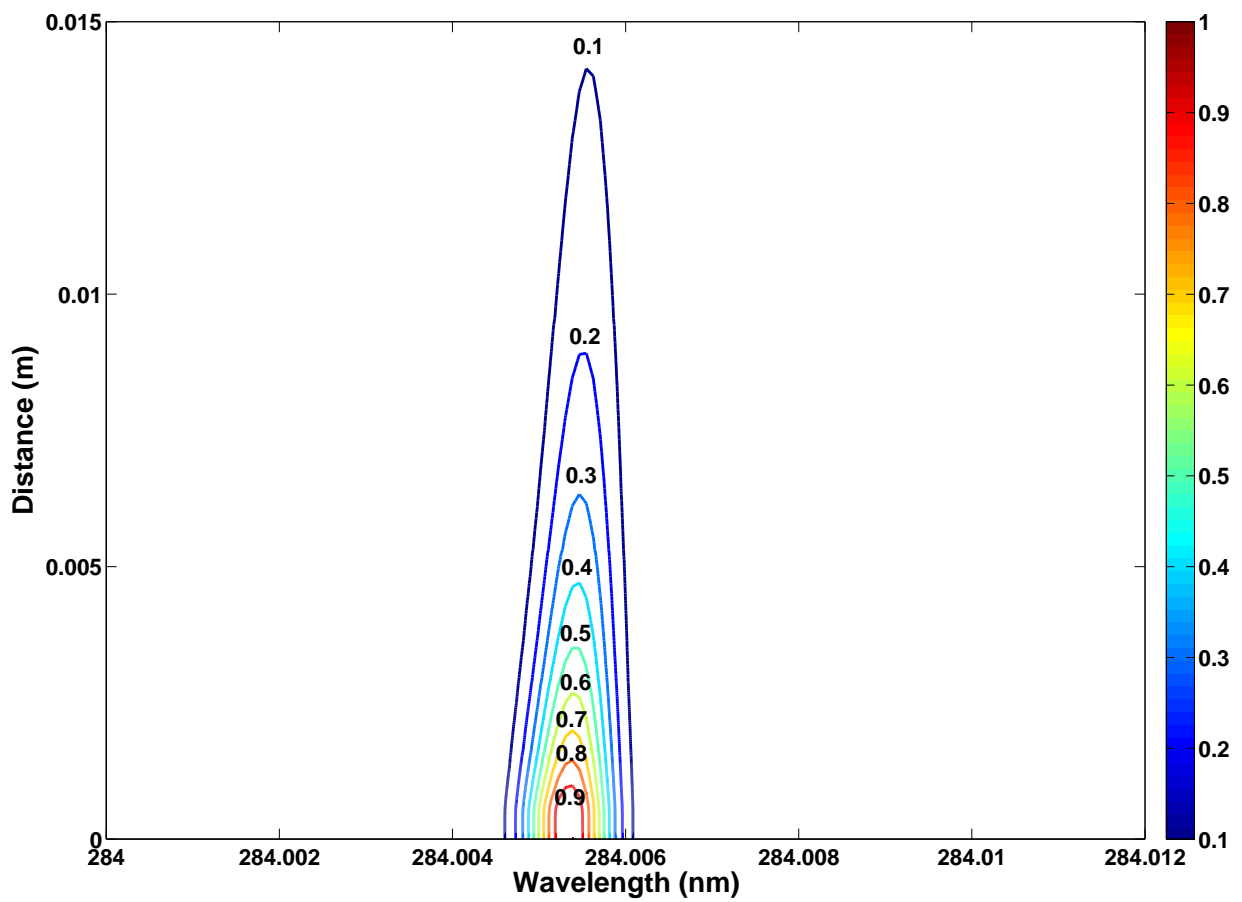

(b) effect of laser line position

Figure 8: 


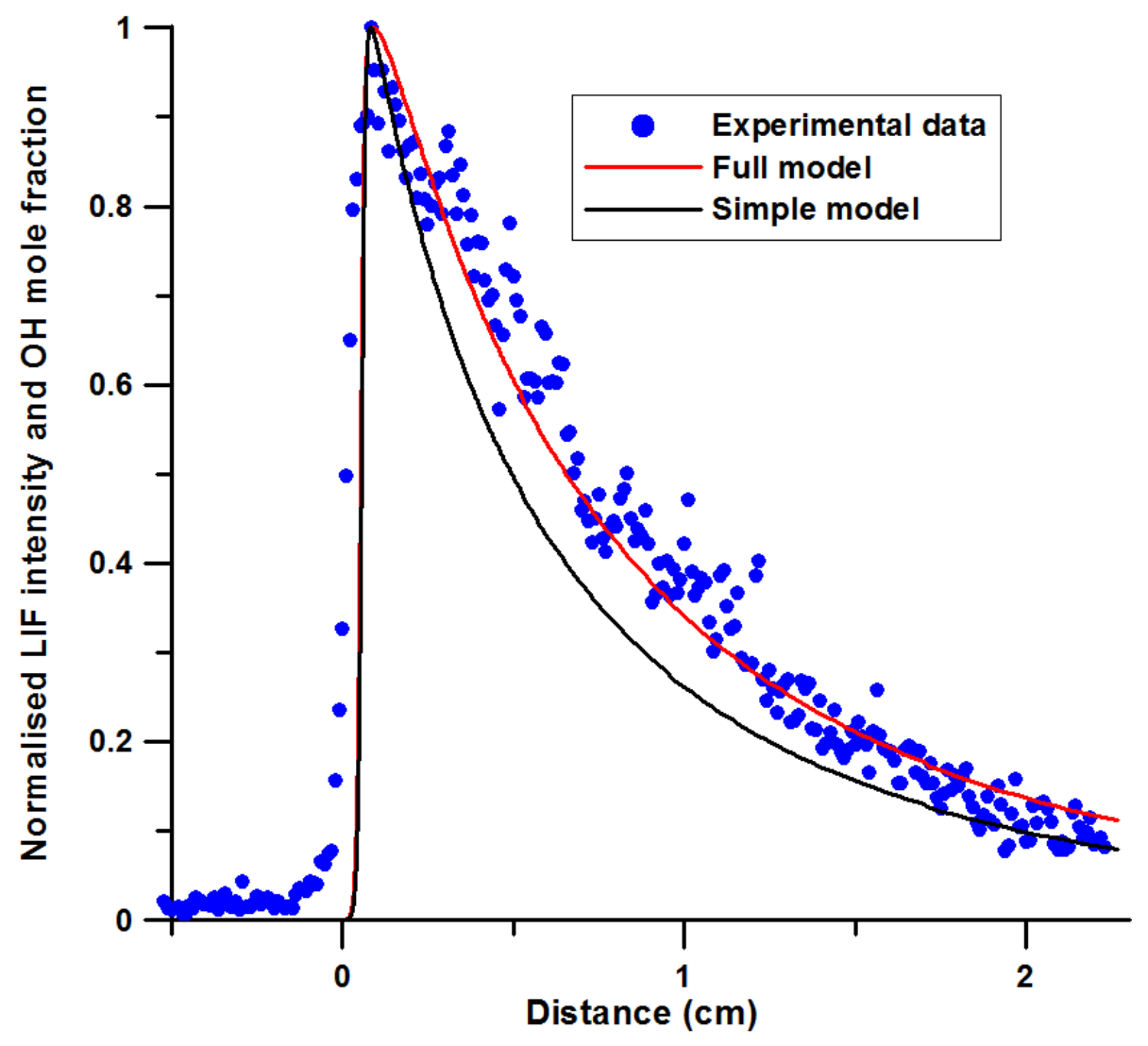

Figure 9: 


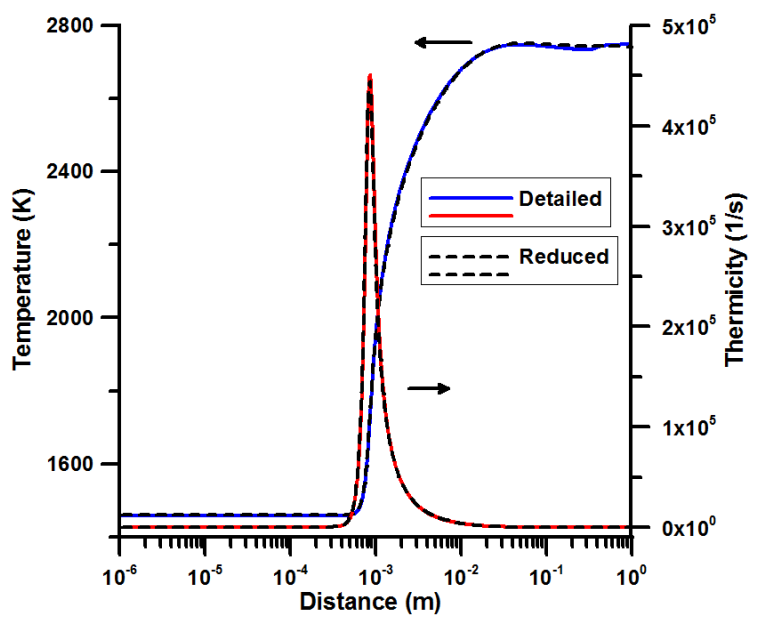

$\mathrm{D}=\mathrm{D}_{C J}$

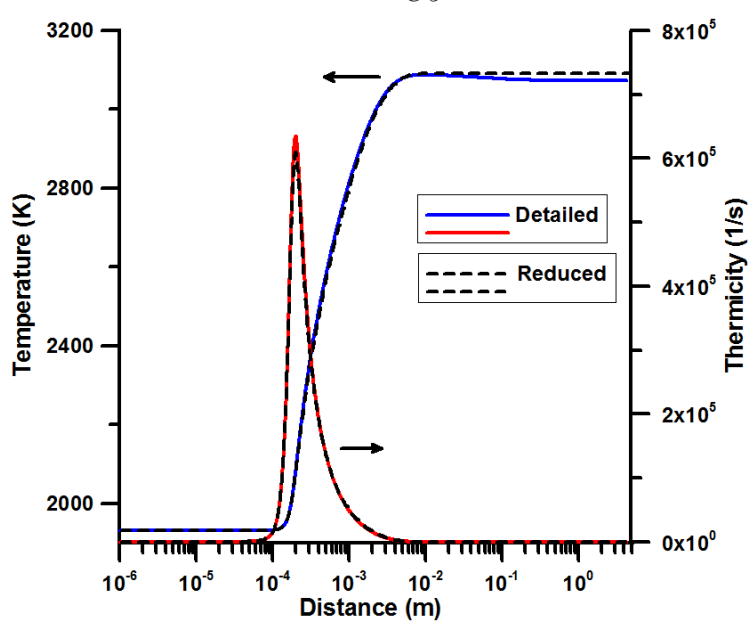

$\mathrm{D}=1.2 \mathrm{D}_{C J}$

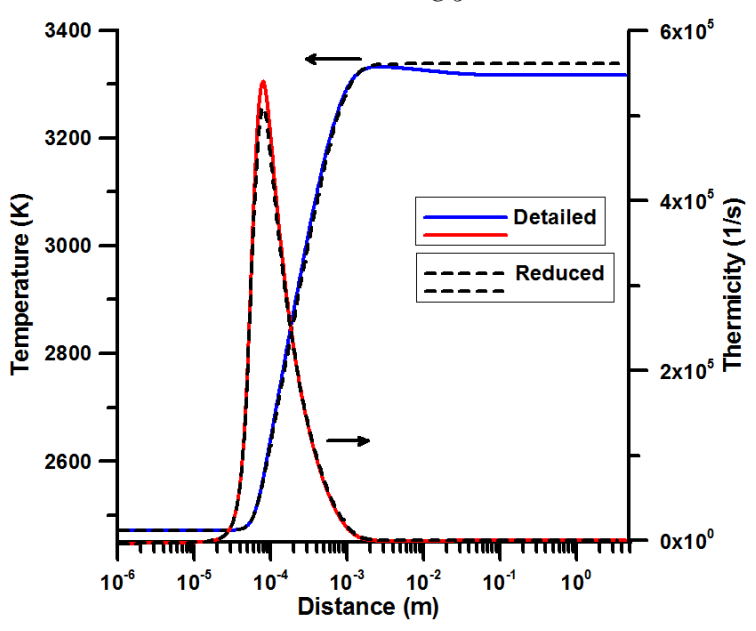

$\mathrm{D}=1.4 \mathrm{D}_{C J}$

Figure 10: 


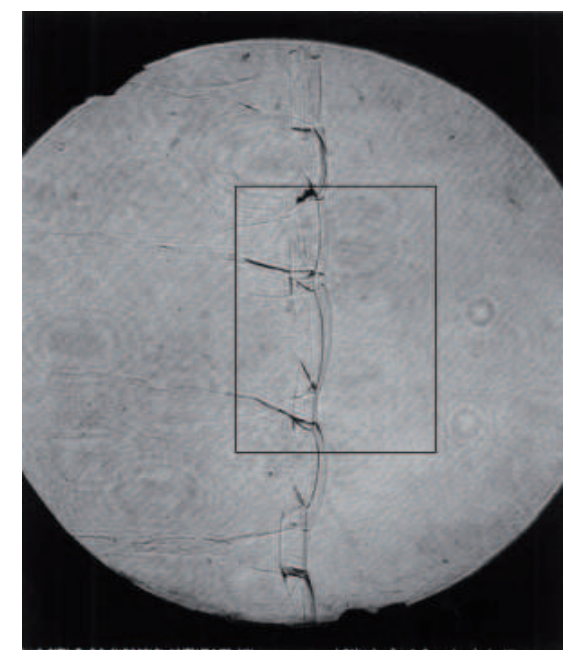

(a) Schlieren

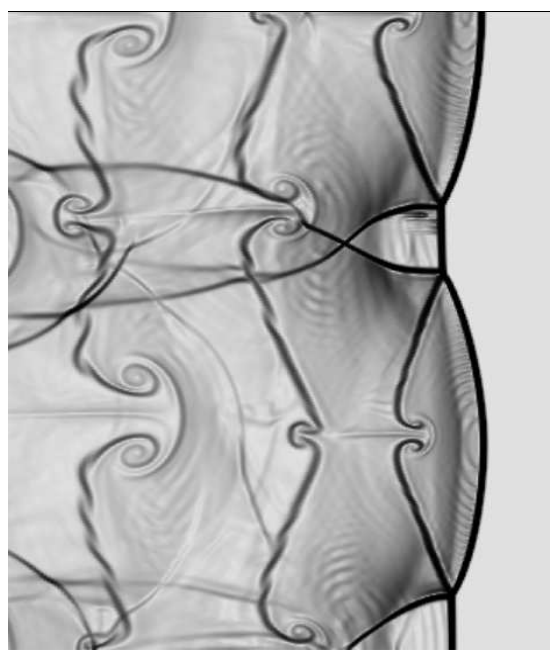

(d) Schlieren

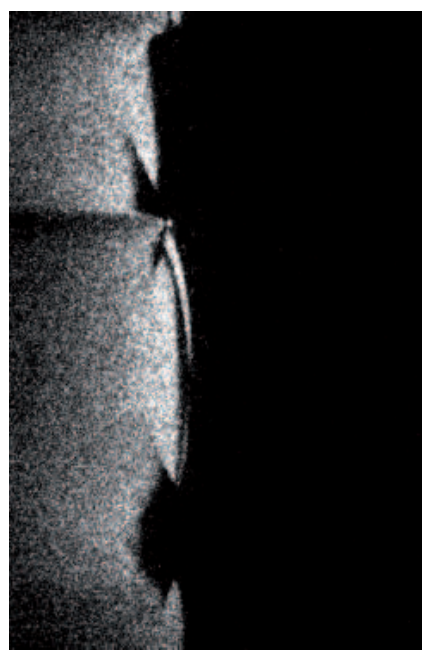

(b) OH PLIF

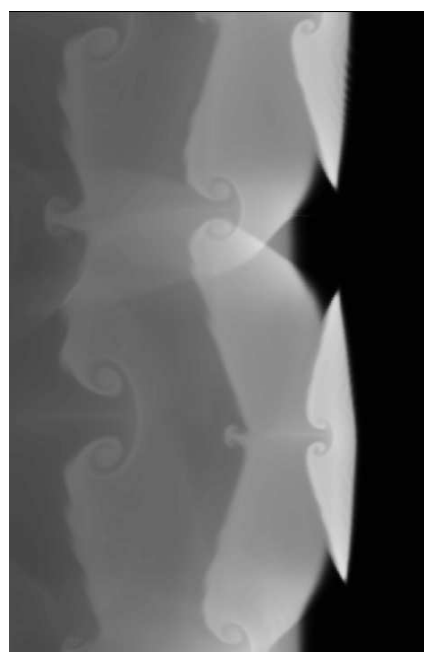

(e) OH PLIF

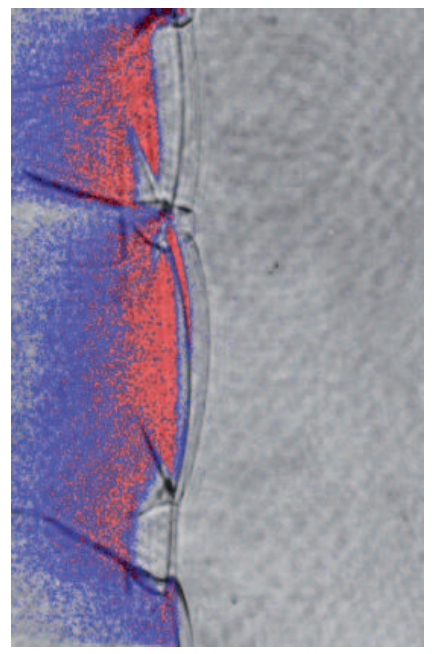

(c) Superimposed

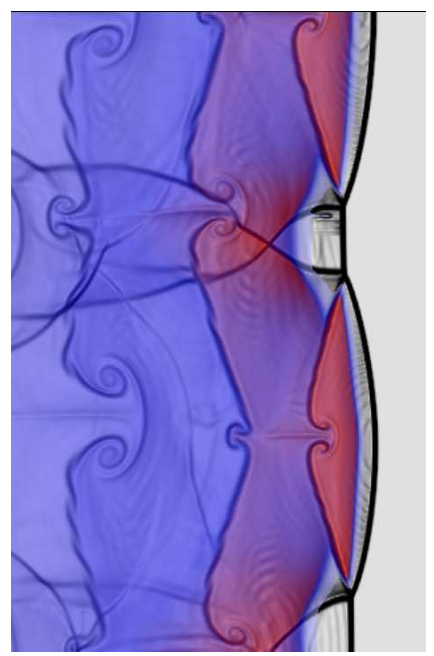

(f) Superimposed

Figure 11: 


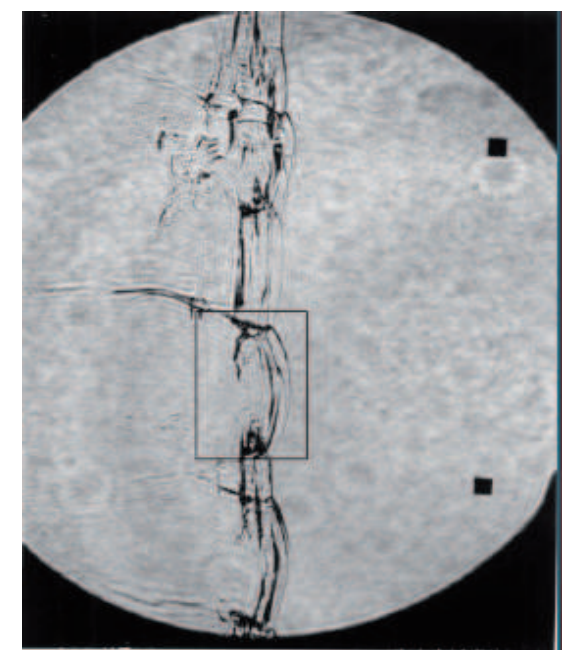

(a) Schlieren

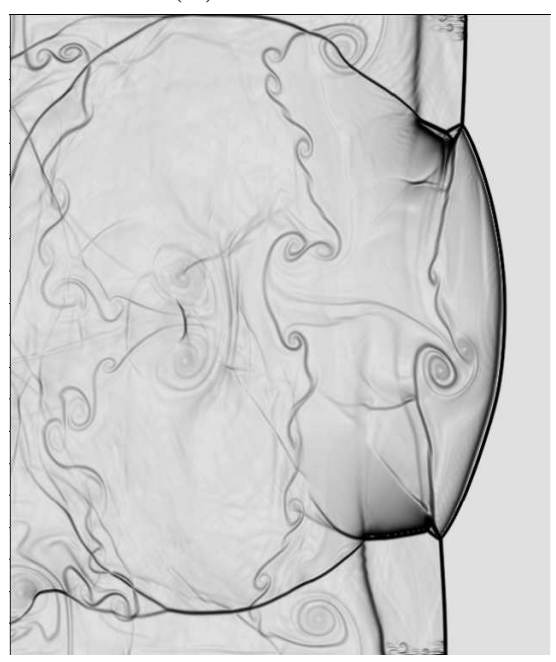

(d) Schlieren

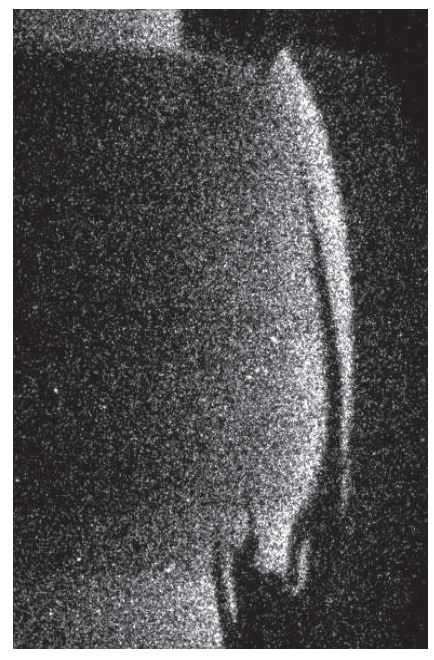

(b) OH PLIF

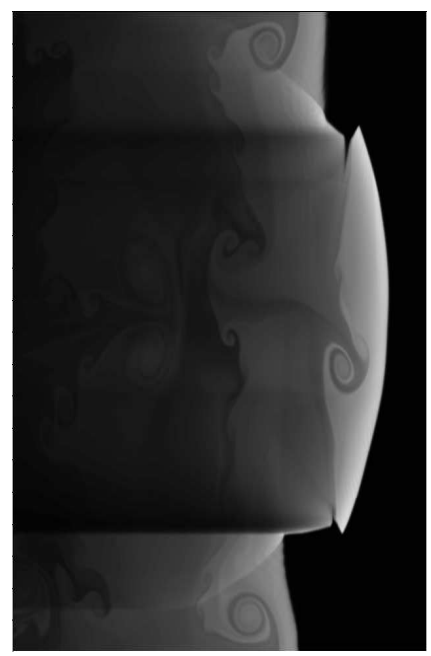

(e) OH PLIF

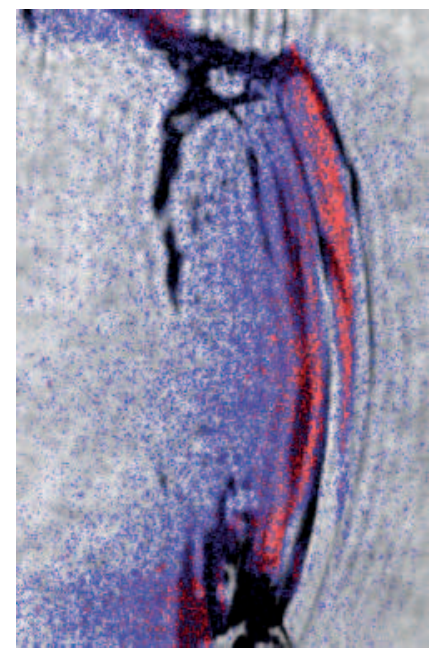

(c) Superimposed

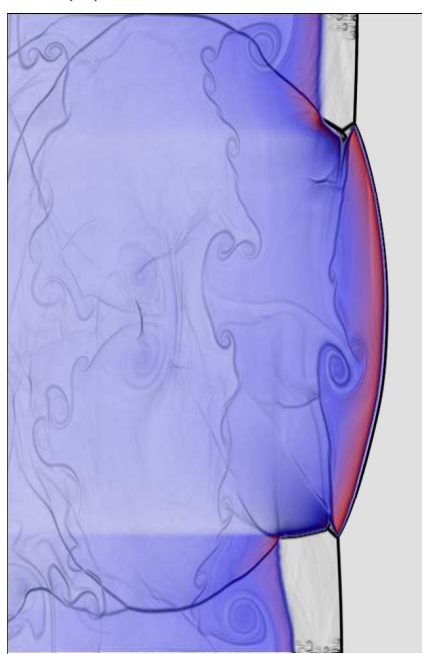

(f) Superimposed

Figure 12: 

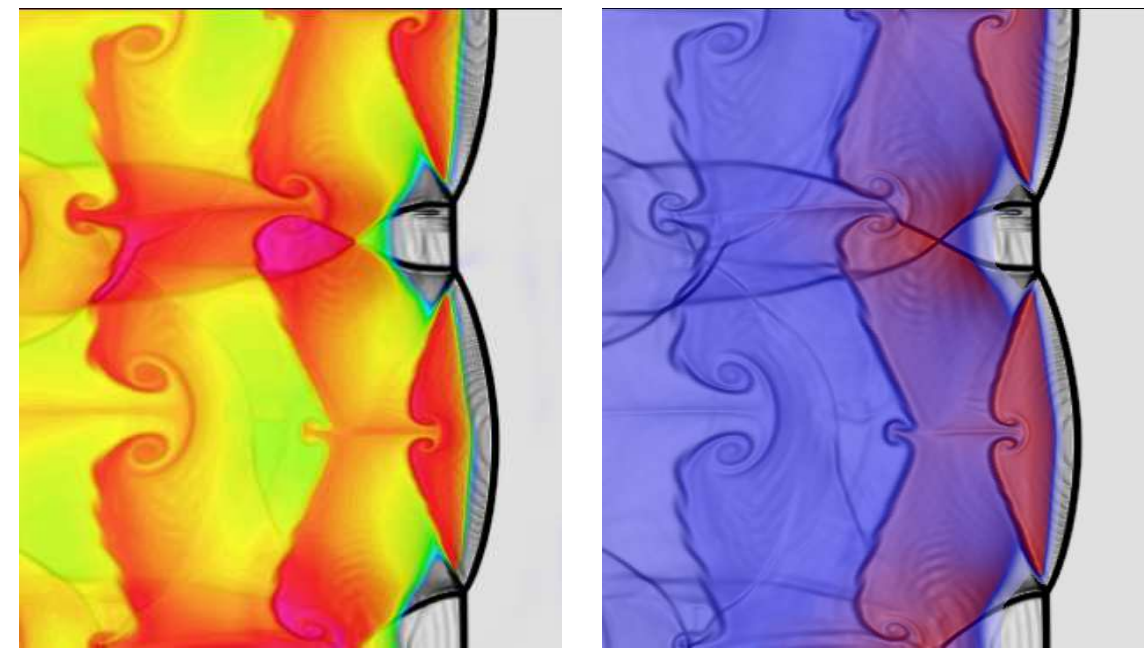

(a) $\mathrm{Y}_{\mathrm{OH}}$ field in $2 \mathrm{H}_{2}-\mathrm{O}_{2}-12 \mathrm{Ar}$

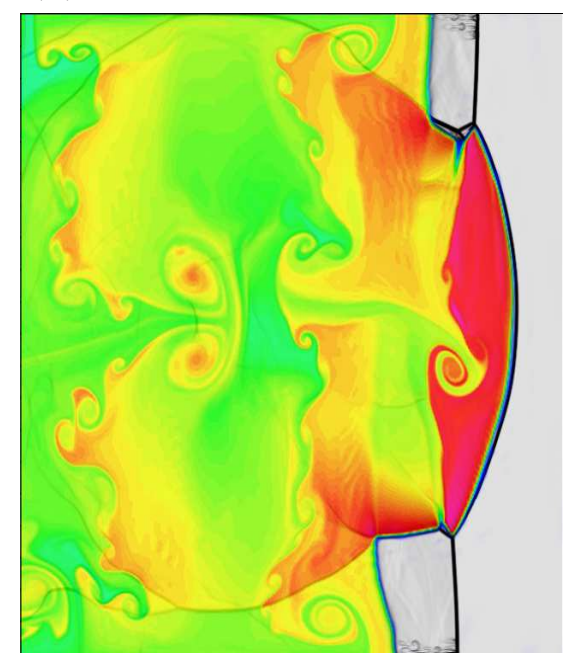

(b) LIF field in $2 \mathrm{H}_{2}-\mathrm{O}_{2}-12 \mathrm{Ar}$

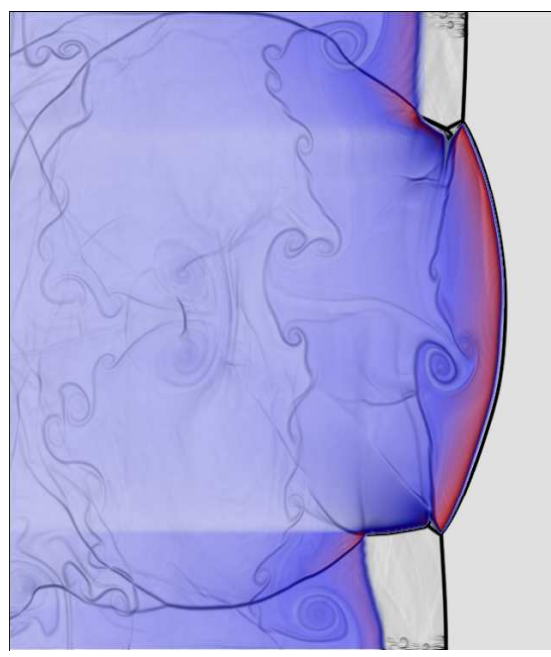

(c) $\mathrm{Y}_{\mathrm{OH}}$ field in $2 \mathrm{H}_{2}-\mathrm{O}_{2}-4.5 \mathrm{~N}_{2}$

(d) LIF field in $2 \mathrm{H}_{2}-\mathrm{O}_{2}-4.5 \mathrm{~N}_{2}$

Figure 13: 


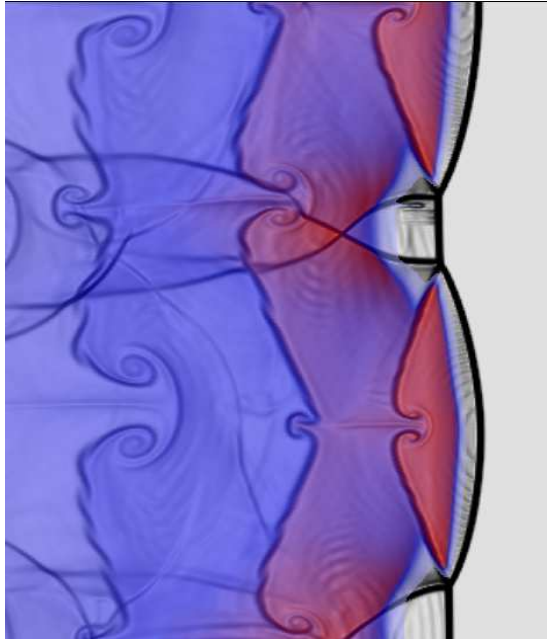

(a) Simulation with $\mathrm{D} / \mathrm{D}_{C J}=1$

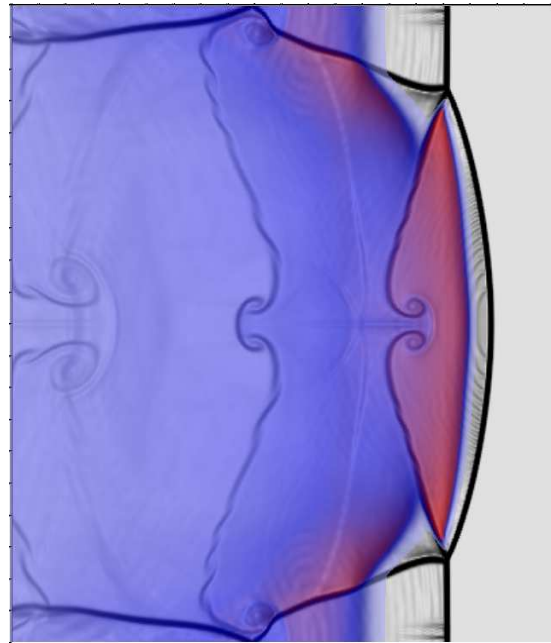

(b) Simulation with $\mathrm{D} / \mathrm{D}_{C J}=0.924$

Figure 14: 


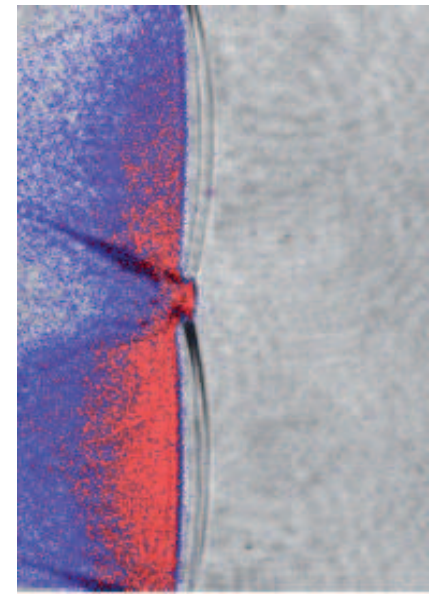

(a) Experimental

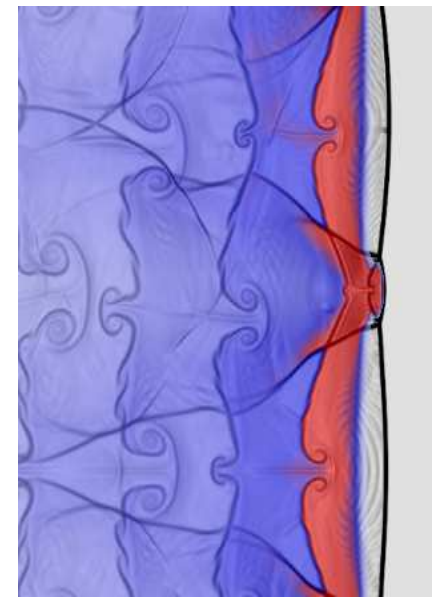

(b) Uniform laser sheet

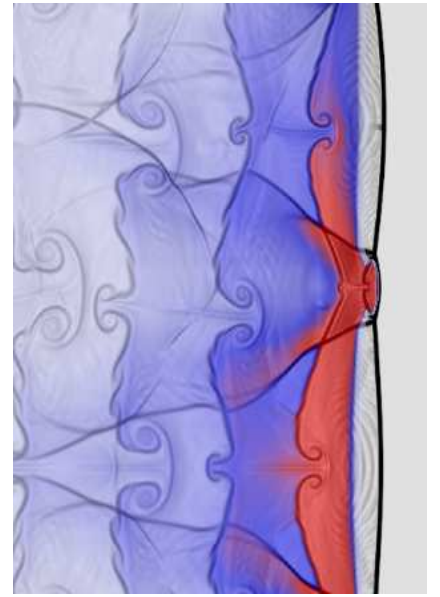

(c) Non-uniform laser sheet and detection threshold

Figure 15: 


\section{List of Tables}

1 Important chemical reactions for the auto-ignition and combustion of stoichiometric $\mathrm{H}_{2}-\mathrm{O}_{2}$-Ar mixtures. $\left(\mathrm{k}=\mathrm{ZT}^{b} \exp (-\mathrm{Ea} / \mathrm{RT})\right) \ldots . . . \quad .49$

2 Important chemical reactions for the auto-ignition and combustion of stoichiometric $\mathrm{H}_{2}-\mathrm{O}_{2}-\mathrm{N}_{2}$ mixtures. $\left(\mathrm{k}=\mathrm{ZT}^{b} \exp (-\mathrm{Ea} / \mathrm{RT})\right) . . . . \quad 50$ 


\begin{tabular}{|c|c|c|c|c|c|}
\hline $\mathrm{N}^{\circ}$ & Reaction & $\mathrm{Z}(\mathrm{cm}-\mathrm{mol}-\mathrm{s}-\mathrm{K})$ & $\mathrm{b}$ & $\mathrm{Ea}(\mathrm{cal} / \mathrm{mol})$ & Ref \\
\hline \multirow[t]{2}{*}{1} & $\mathrm{H}_{2}+\mathrm{M}=2 \mathrm{H}+\mathrm{M}$ & $4.57 \mathrm{E}+19$ & -1.4 & 104423 & [71] \\
\hline & enhanced: $\mathrm{H}_{2}=2.5 / \mathrm{H}_{2} \mathrm{O}=12 / \mathrm{Ar}=0$ & & & & \\
\hline 2 & $\mathrm{H}_{2}+\mathrm{AR}=2 \mathrm{H}+\mathrm{Ar}$ & $5.84 \mathrm{E}+18$ & -1.1 & 104423 & [71] \\
\hline 3 & $\mathrm{H}_{2}+\mathrm{O}_{2}=2 \mathrm{OH}$ & $2.50 \mathrm{E}+12$ & 0 & 39016 & [72] \\
\hline 4 & $3 \mathrm{H}=\mathrm{H}_{2}+\mathrm{H}$ & $3.20 \mathrm{E}+15$ & 0 & 0 & [72] \\
\hline 5 & $\mathrm{O}+\mathrm{H}_{2}=\mathrm{H}+\mathrm{OH}$ & $5.08 \mathrm{E}+04$ & 2.67 & 6293 & [73] \\
\hline 6 & $\mathrm{H}+\mathrm{O}_{2}=\mathrm{O}+\mathrm{OH}$ & $1.91 \mathrm{E}+14$ & 0 & 16446 & {$[74]$} \\
\hline $7 \mathrm{a}$ & $\mathrm{H}+\mathrm{O}_{2}=\mathrm{HO}_{2}$ & $1.48 \mathrm{E}+12$ & 0.6 & 0 & {$[75]$} \\
\hline \multirow[t]{2}{*}{$7 \mathrm{~b}$} & $\mathrm{H}+\mathrm{O}_{2}+\mathrm{M}=\mathrm{HO}_{2}+\mathrm{M}$ & $3.48 \mathrm{E}+16$ & -0.411 & -1115 & [75] \\
\hline & enhanced: $\mathrm{H}_{2}=2.5 / \mathrm{H}_{2} \mathrm{O}=12 / \mathrm{Ar}=0$ & & & & \\
\hline $8 \mathrm{a}$ & $\mathrm{H}+\mathrm{O}_{2}=\mathrm{HO}_{2}$ & $1.48 \mathrm{E}+13$ & 0.6 & 0 & [76] \\
\hline $8 \mathrm{~b}$ & $\mathrm{H}+\mathrm{O}_{2}+\mathrm{Ar}=\mathrm{HO}_{2}+\mathrm{Ar}$ & $1.49 \mathrm{E}+15$ & 0 & -1000 & {$[76]$} \\
\hline \multirow[t]{2}{*}{9} & $\mathrm{H}+\mathrm{O}+\mathrm{M}=\mathrm{OH}+\mathrm{M}$ & $4.71 \mathrm{E}+18$ & -1 & 0 & [71] \\
\hline & enhanced: $\mathrm{H}_{2}=2.5 / \mathrm{H}_{2} \mathrm{O}=12 / \mathrm{Ar}=0.75$ & & & & \\
\hline 10 & $\mathrm{OH}+\mathrm{H}_{2}=\mathrm{H}_{2} \mathrm{O}+\mathrm{H}$ & $2.16 \mathrm{E}+08$ & 1.51 & 3431 & {$[77]$} \\
\hline 11 & $\mathrm{H}_{2} \mathrm{O}+\mathrm{O}=2 \mathrm{OH}$ & $2.97 \mathrm{E}+06$ & 2.02 & 13406 & [78] \\
\hline $12 \mathrm{a}$ & $\mathrm{H}_{2} \mathrm{O}_{2}=2 \mathrm{OH}$ & $2.95 \mathrm{E}+14$ & 0 & 48450 & [79] \\
\hline \multirow[t]{2}{*}{$12 \mathrm{~b}$} & $\mathrm{H}_{2} \mathrm{O}_{2}+\mathrm{M}=2 \mathrm{OH}+\mathrm{M}$ & $1.20 \mathrm{E}+17$ & 0 & 45519 & [79] \\
\hline & enhanced: $\mathrm{H}_{2}=2.5 / \mathrm{H}_{2} \mathrm{O}=12$ & & & & \\
\hline \multirow[t]{2}{*}{13} & $\mathrm{OH}+\mathrm{H}+\mathrm{M}=\mathrm{H}_{2} \mathrm{O}+\mathrm{M}$ & $2.21 \mathrm{E}+22$ & -2 & 0 & [71] \\
\hline & enhanced: $\mathrm{H}_{2}=2.5 / \mathrm{H}_{2} \mathrm{O}=12 / \mathrm{Ar}=0$ & & & & \\
\hline 14 & $\mathrm{OH}+\mathrm{H}+\mathrm{AR}=\mathrm{H}_{2} \mathrm{O}+\mathrm{Ar}$ & $8.41 \mathrm{E}+21$ & -2 & 0 & [71] \\
\hline 15 & $\mathrm{HO}_{2}+\mathrm{H}=\mathrm{H}_{2}+\mathrm{O}_{2}$ & $1.66 \mathrm{E}+13$ & 0 & 823 & [80] \\
\hline 16 & $\mathrm{HO}_{2}+\mathrm{H}=2 \mathrm{OH}$ & $7.08 \mathrm{E}+13$ & 0 & 295 & [80] \\
\hline 17 & $\mathrm{H}_{2} \mathrm{O}_{2}+\mathrm{OH}=\mathrm{H}_{2} \mathrm{O}+\mathrm{HO}_{2}$ & $5.80 \mathrm{E}+14$ & 0 & 9561 & [81] \\
\hline
\end{tabular}


Table 2:

\begin{tabular}{|c|c|c|c|c|c|}
\hline $\mathrm{N}^{\circ}$ & Reaction & $\mathrm{Z}(\mathrm{cm}-\mathrm{mol}-\mathrm{s}-\mathrm{K})$ & b & $\mathrm{Ea}(\mathrm{cal} / \mathrm{mol})$ & Ref \\
\hline 1 & $\begin{array}{l}\mathrm{H}_{2}+\mathrm{M}=2 \mathrm{H}+\mathrm{M} \\
\text { enhanced: } \mathrm{H}_{2}=2.5 / \mathrm{H}_{2} \mathrm{O}=12\end{array}$ & $4.57 \mathrm{E}+19$ & -1.4 & 104423 & {$[71]$} \\
\hline 2 & $\mathrm{H}_{2}+\mathrm{O}_{2}=2 \mathrm{OH}$ & $2.50 \mathrm{E}+12$ & 0 & 39016 & {$[72]$} \\
\hline 3 & $\mathrm{H}+\mathrm{HO}_{2}=\mathrm{H}_{2} \mathrm{O}+\mathrm{O}$ & $3.00 \mathrm{E}+13$ & 0 & 866 & {$[72]$} \\
\hline 4 & $\mathrm{O}+\mathrm{H}_{2}=\mathrm{H}+\mathrm{OH}$ & $5.08 \mathrm{E}+04$ & 2.67 & 6293 & {$[73]$} \\
\hline 5 & $\mathrm{H}+\mathrm{O}_{2}=\mathrm{O}+\mathrm{OH}$ & $1.91 \mathrm{E}+14$ & 0 & 16446 & {$[74]$} \\
\hline $6 a$ & $\mathrm{H}+\mathrm{O}_{2}=\mathrm{HO}_{2}$ & $1.48 \mathrm{E}+12$ & 0.6 & 0 & {$[75]$} \\
\hline $6 b$ & $\begin{array}{l}\mathrm{H}+\mathrm{O}_{2}+\mathrm{M}=\mathrm{HO}_{2}+\mathrm{M} \\
\text { enhanced: } \mathrm{H}_{2}=2.5 / \mathrm{H}_{2} \mathrm{O}=12\end{array}$ & $3.48 \mathrm{E}+16$ & -0.411 & -1115 & {$[75]$} \\
\hline 7 & $\begin{array}{l}\mathrm{H}+\mathrm{O}+\mathrm{M}=\mathrm{OH}+\mathrm{M} \\
\text { enhanced: } \mathrm{H}_{2}=2.5 / \mathrm{H}_{2} \mathrm{O}=12 / \mathrm{Ar}=0.75\end{array}$ & $4.71 \mathrm{E}+18$ & -1 & 0 & {$[71]$} \\
\hline 8 & $\mathrm{OH}+\mathrm{H}_{2}=\mathrm{H}_{2} \mathrm{O}+\mathrm{H}$ & $2.16 \mathrm{E}+08$ & 1.51 & 3431 & {$[77]$} \\
\hline 9 & $\begin{array}{l}\mathrm{OH}+\mathrm{H}+\mathrm{M}=\mathrm{H}_{2} \mathrm{O}+\mathrm{M} \\
\text { enhanced: } \mathrm{H}_{2}=2.5 / \mathrm{H}_{2} \mathrm{O}=12\end{array}$ & $2.21 \mathrm{E}+22$ & -2 & 0 & {$[71]$} \\
\hline 10 & $\mathrm{HO}_{2}+\mathrm{H}=\mathrm{H}_{2}+\mathrm{O}_{2}$ & $1.66 \mathrm{E}+13$ & 0 & 823 & {$[80]$} \\
\hline 11 & $\mathrm{HO}_{2}+\mathrm{H}=2 \mathrm{OH}$ & $7.08 \mathrm{E}+13$ & 0 & 295 & {$[80]$} \\
\hline 12 & $\mathrm{HO}_{2}+\mathrm{OH}=\mathrm{H}_{2} \mathrm{O}+\mathrm{O}_{2}$ & $2.89 \mathrm{E}+13$ & 0 & -250 & {$[82]$} \\
\hline
\end{tabular}

